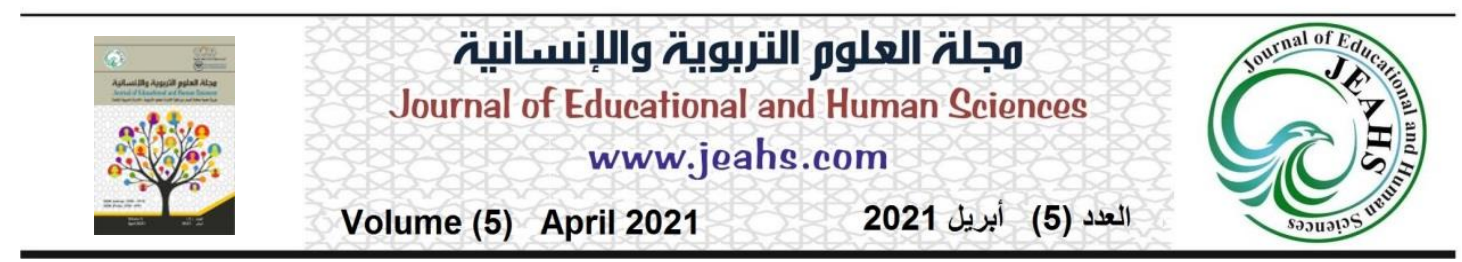

\title{
الاستعمار الكولينيالي الجديد (الكونغو انموذجاً)
}

\author{
م.د. مصعب عطية ذنون الزبيدي

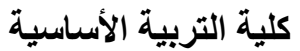 \\ جامعة سومر - العراق التربة \\ البريد الاكتروني: mussabateya@gmail.com
}

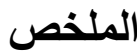

تميز الوضع الدولي بعد إنتهاء الحرب العالمية الثانية بظهور قوتين جديدنين هما الولايات المتحدة الامريكية

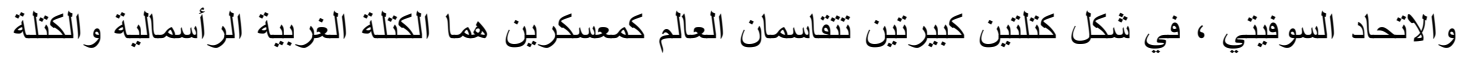
الثرقية الثيو عية ، و لاشك الن التنافس الصريح و الخفي بين هذين المعسكرين لكسب المين الميديد من التفوق ولتأمين

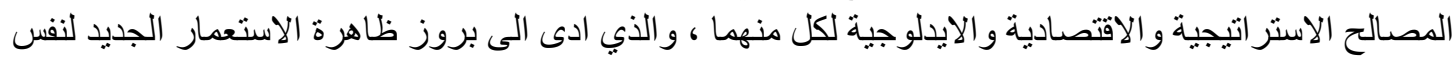

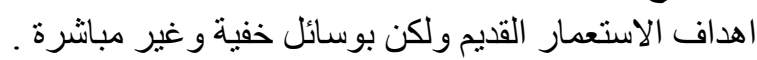

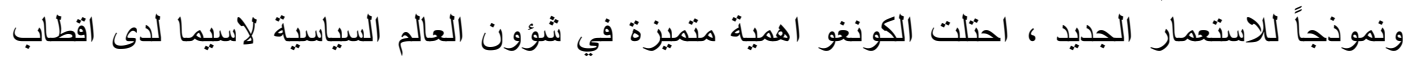

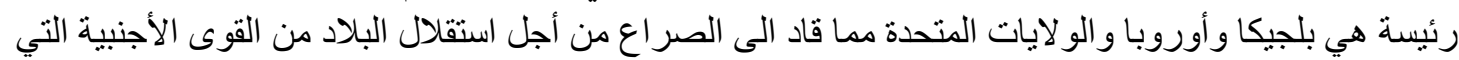

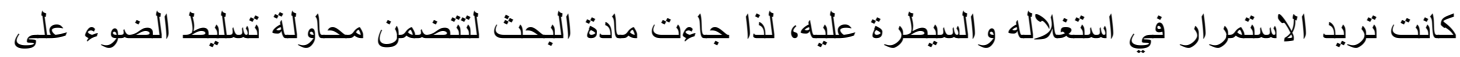

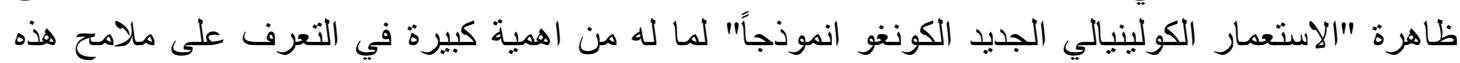
الظاهرة الاستعمارية. تم تقسيم البحث الى مقدمة وثناثة محاور وخاتمة ، جاء بالمحور الاول بعنوان "الاستعمار الكولينيالي الجديد

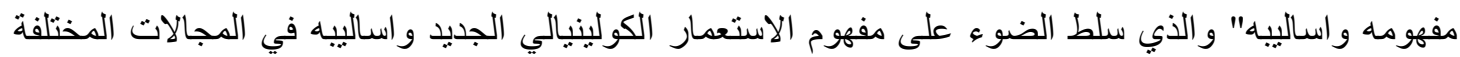

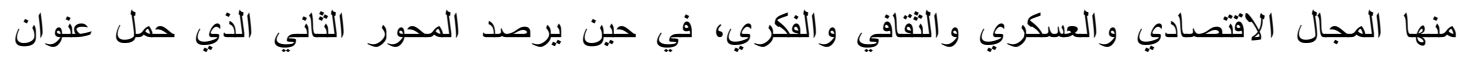

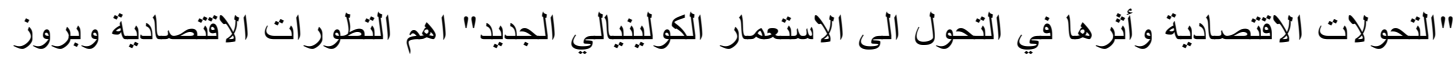

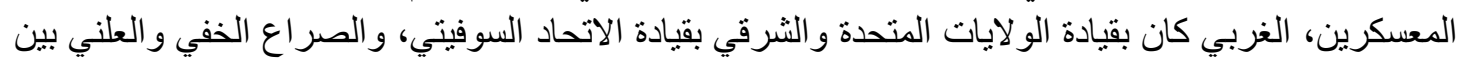

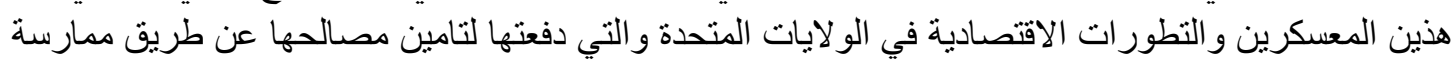

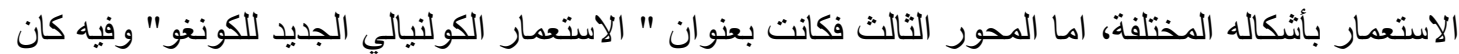

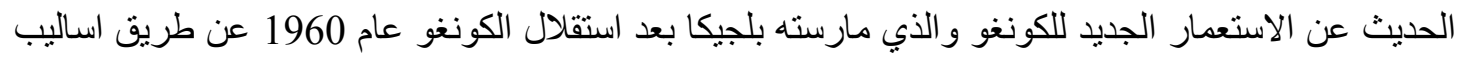

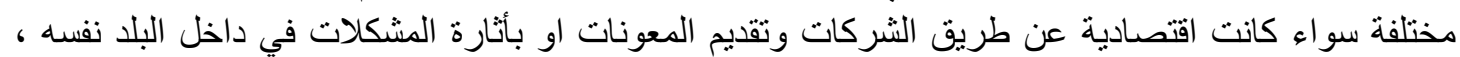
و التي كان للو لايات المتحدة دور كبير في ذللك، لحماية مصالحها. الكلمات المفتاحية: الاستعمار الكولينيالي، الكونغو. 


\title{
Neo-Colonial Colonialism (Congo as a model)
}

\author{
Dr. Musab Attia Thanoun Al-Zubaidi \\ Faculty of Basic Education \\ Sumer University - Iraq \\ Email: mussabateya@gmail.com
}

\begin{abstract}
The international situation after the end of the Second World War was characterized by the emergence of two new powers, the United States of America and the Soviet Union, in the form of two large blocs sharing the world as two camps: the capitalist western bloc and the communist eastern bloc, and there is no doubt that the open and hidden competition between these two camps to gain more supremacy and to secure strategic, economic and ideological interests For each of them, which led to the emergence of the phenomenon of new colonialism with the same goals of old colonialism, but through hidden and indirect means. As an example of the new colonialism, the Congo occupied a distinguished importance in the political affairs of the world, especially among the main poles, namely Belgium, Europe and the United States, which led to the struggle for the country's independence from foreign powers that wanted to continue to exploit and control it, so the research material came to include an attempt to shed light on The phenomenon of "neo-colonial colonialism, the Congo as a model" because of its great importance in identifying the features of this colonial phenomenon. The research was divided into an introduction, three axes, and a conclusion. The first axis came with the title "The New Colonial Colonialism, Its Concept and Methods," which shed light on the concept of new colonial colonialism and its methods in various fields, including the economic, military, cultural and intellectual sphere, while the second axis, titled "Economic Transformations" And its effect on the transition to neo-colonial colonialism, "the most important economic developments and the emergence of the two camps, the Western was led by the United States and the Eastern led by the Soviet Union, and the hidden and overt conflict between these two camps and the economic developments in the United States that pushed it to secure its interests by practicing colonialism in its various forms, while the third axis was Entitled "the new colonial colonization of the Congo", in which the discussion was about the new colonialism of the Congo, which was practiced by Belgium after the independence of the Congo in 1960 through various methods, whether economic through companies, providing aid, or stirring up problems within the country itself, in which the United States had a major role in that to protect their interests.
\end{abstract}

Keywords: Colonial colonization, Congo. 


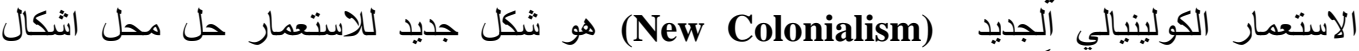

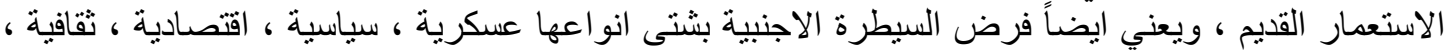

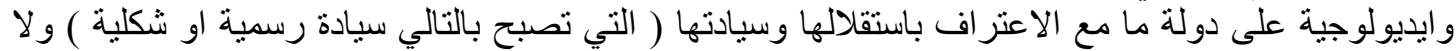

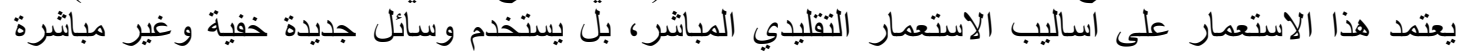

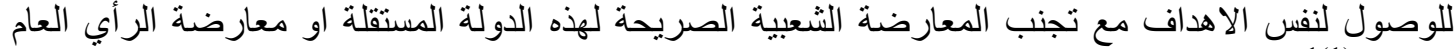

كما يمكن ان يعرف بانه هو السياسة الكولينيالية التي تتنهجها الدول الامبريالية في ظروف تلفئ تفكلك و انهيار

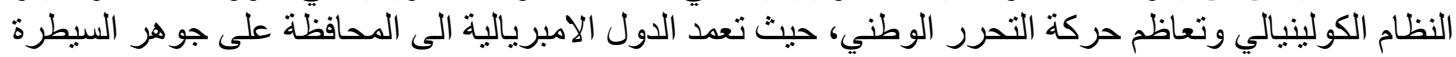

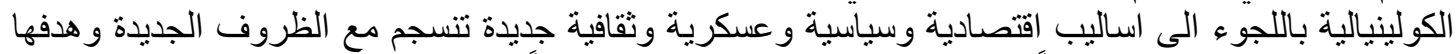

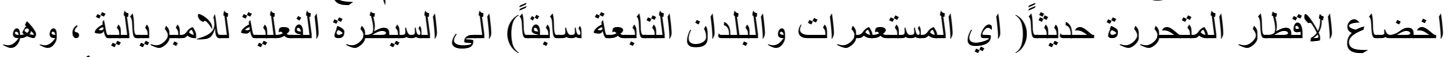

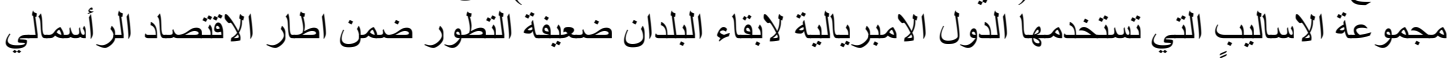

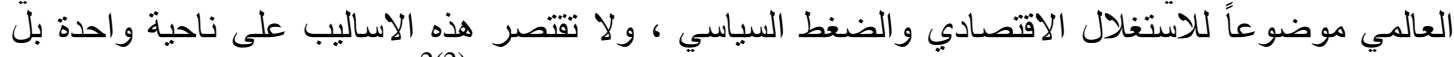

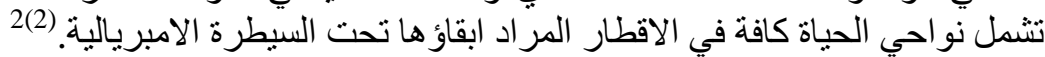

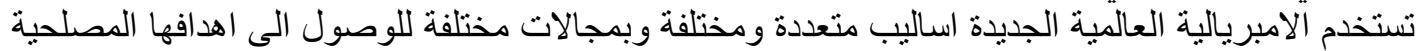

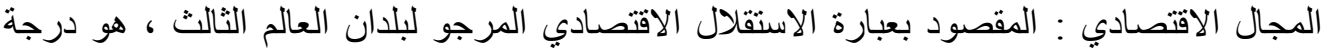
ومنها :

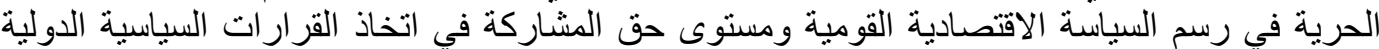

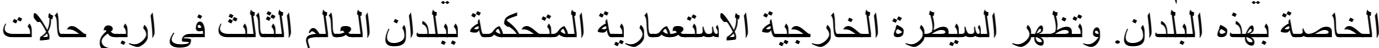

اقتصادية اساسية: (1)

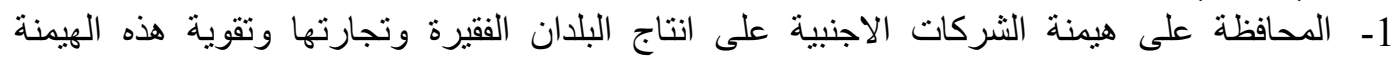

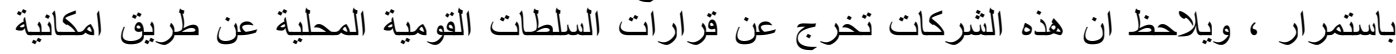

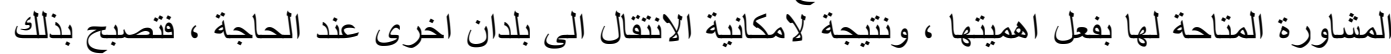

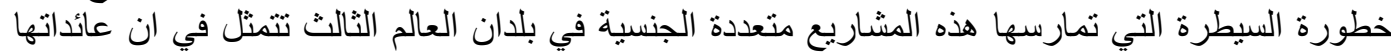

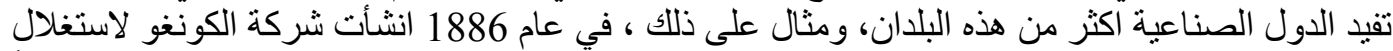

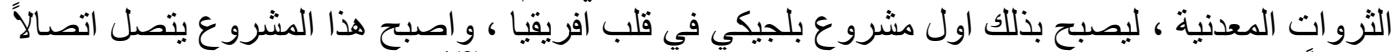

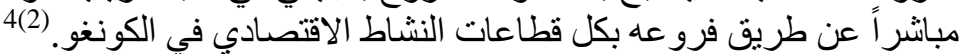

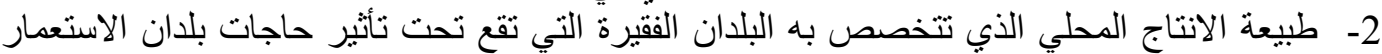

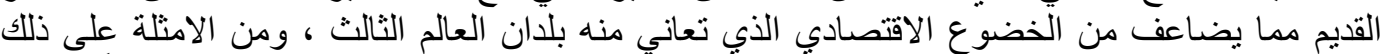

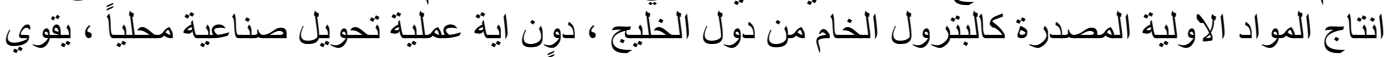

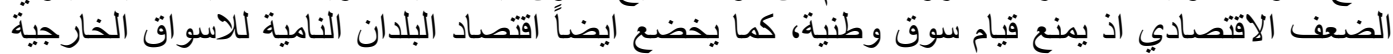

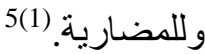

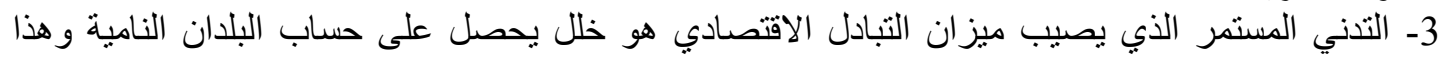

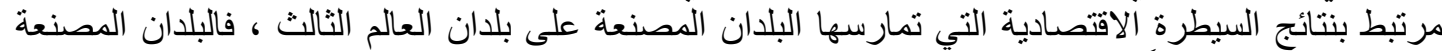

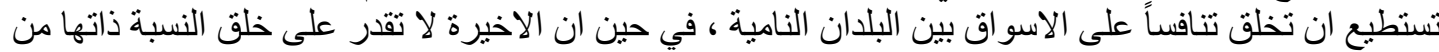

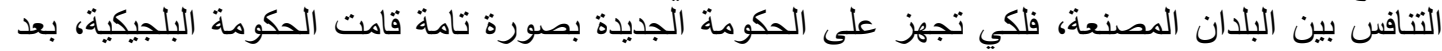

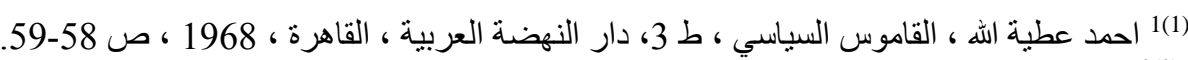

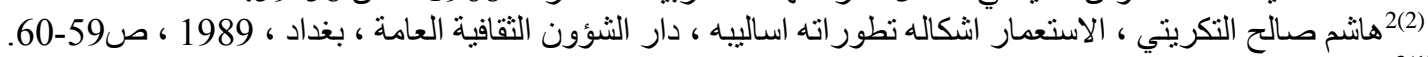

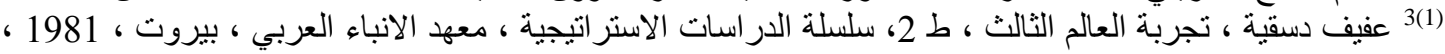

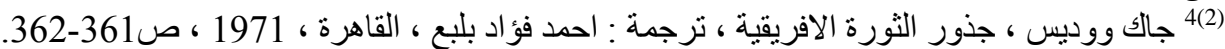

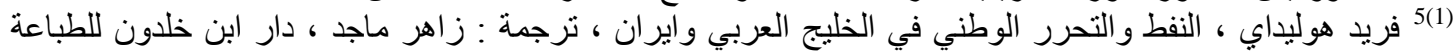
و النشر ، بيروت، 


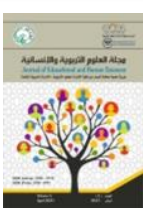

مجلة العلوم التربوية والإنسانية

Journal of Educational and Human Sciences www.jeahs.com

Volume (5) April 2021

العدد (5) أبريل 2021

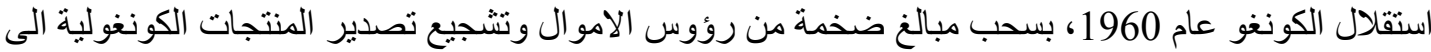

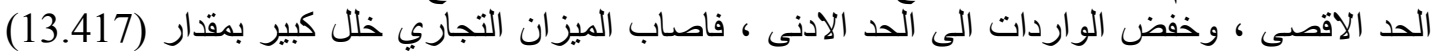

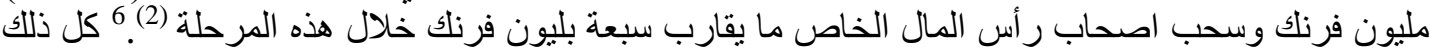

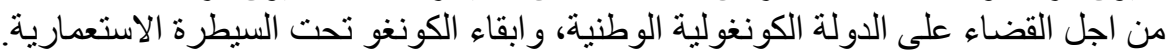

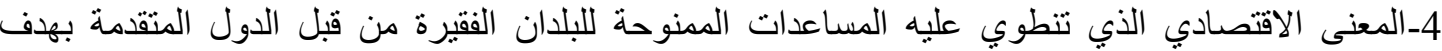

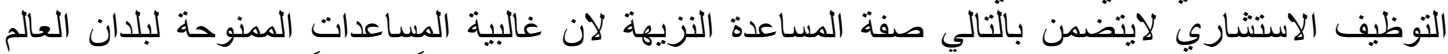

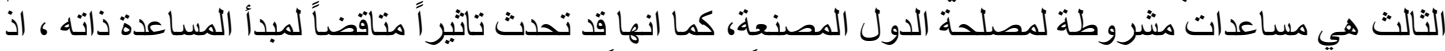

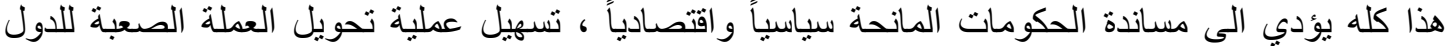

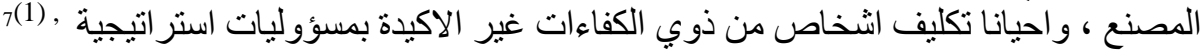

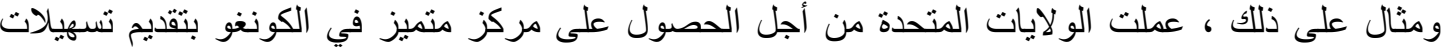

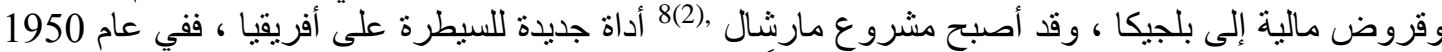

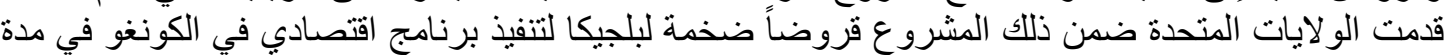

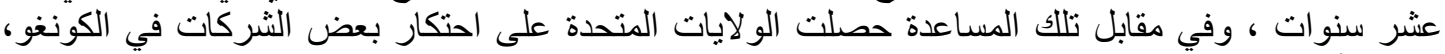

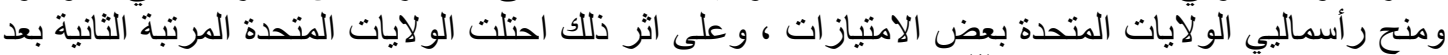

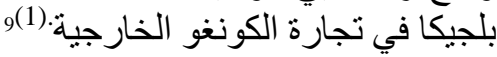

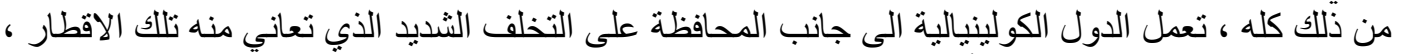

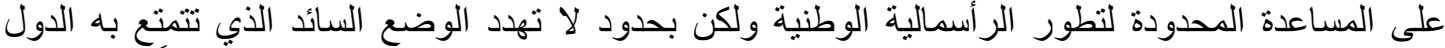

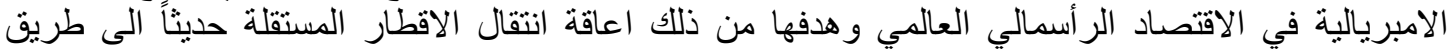

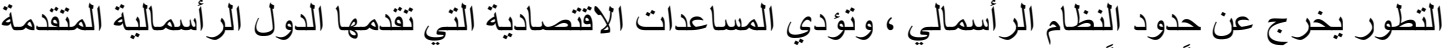

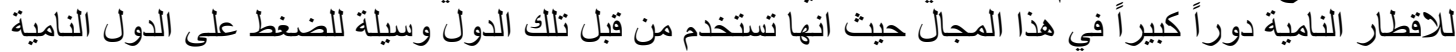

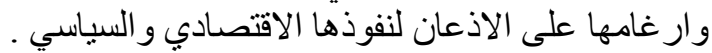

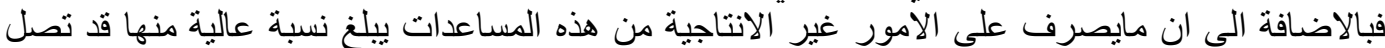

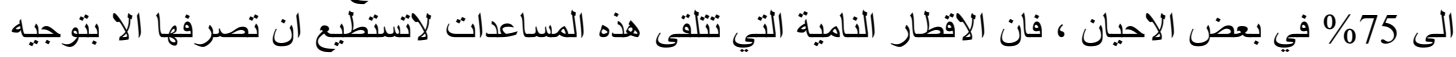

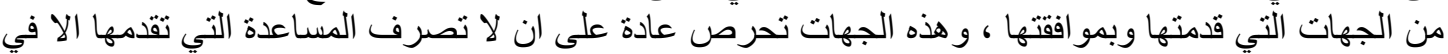

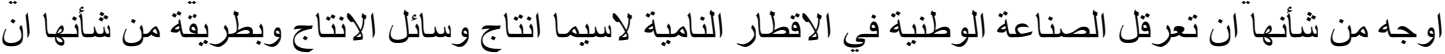

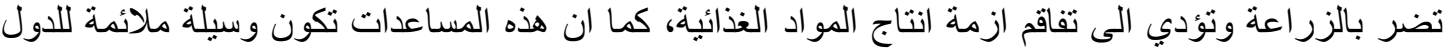

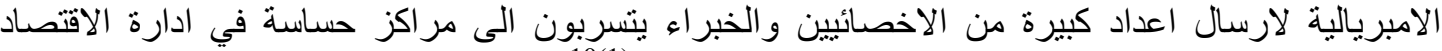

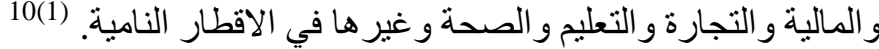

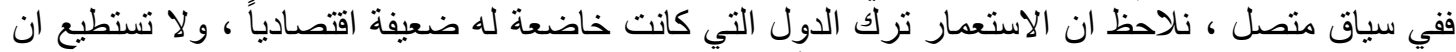

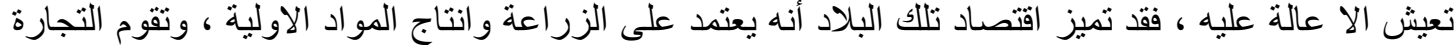

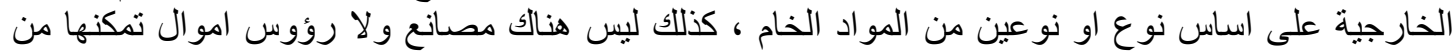

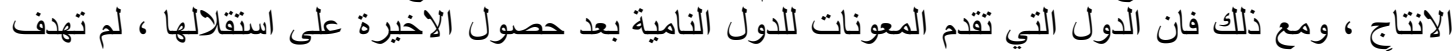

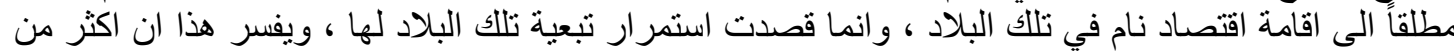

6(2) كوامي نكروما ، الاستعمار الجديد اخر مراحل الامبريالية ، ترجمة : عبد الحميد حمدي ، د.م ، 1966، ص 259-

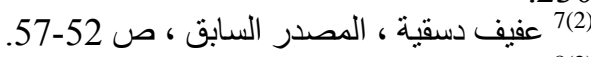

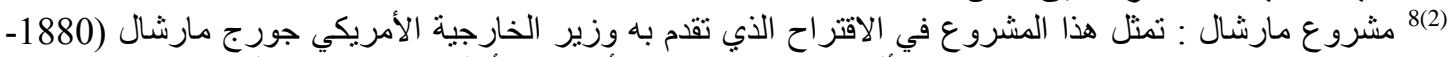

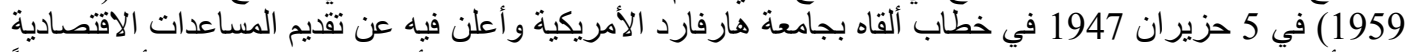

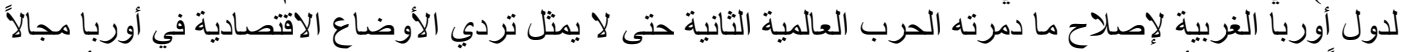

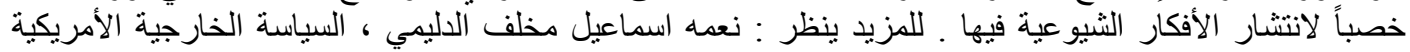

(1)و التر رودني ، أورباو التخلف في أفريقيا ، ترجمة أحمد القصير ، الكويت ، 1988 ، ص284-285.

10(1) 10 هاثش صالح التكريتي ، المصدر السابق ، ص 60-61. 


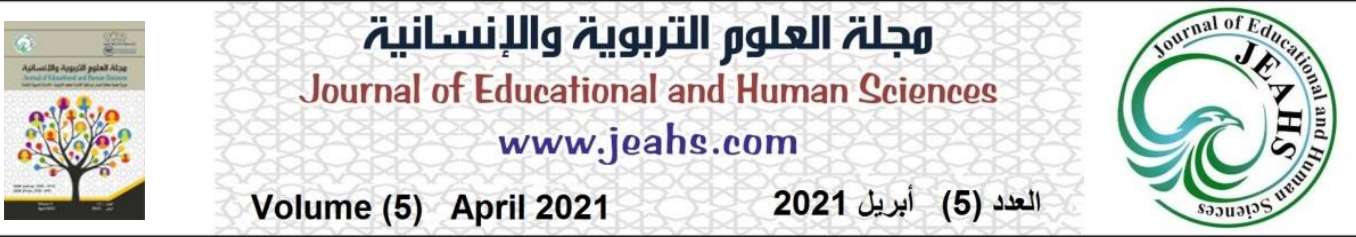

(60\%) من التوظيفات الاجنبية في هذه البلدان توظف في الزراعة واستخر اج المعادن ، اما حصة الصناعة

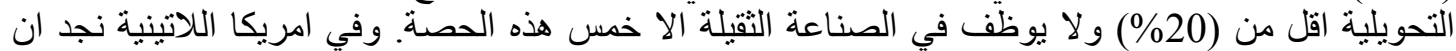

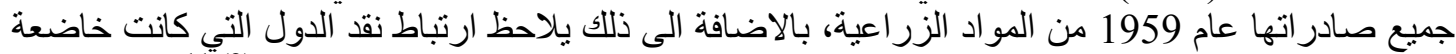

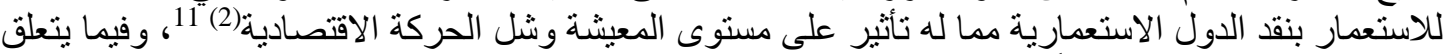

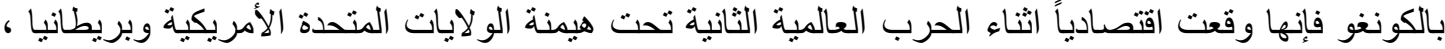

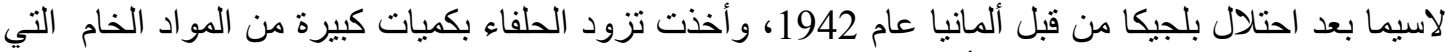

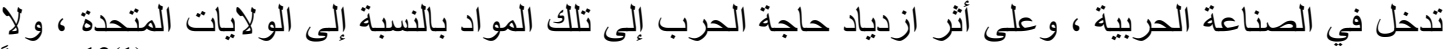

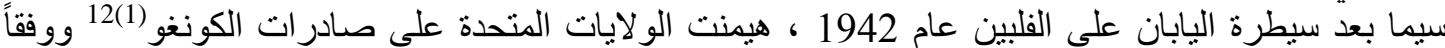

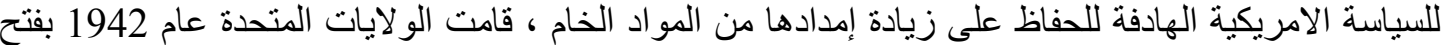

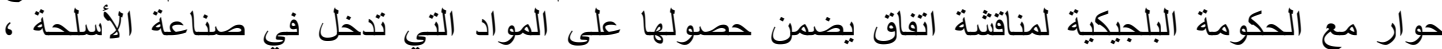

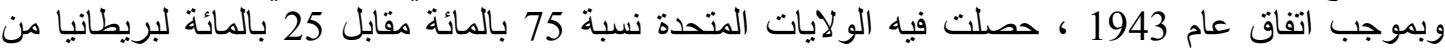

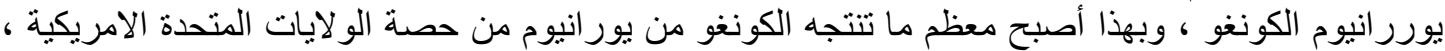

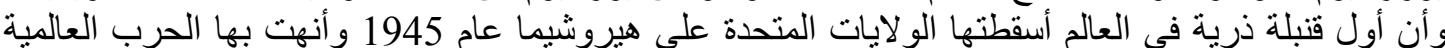

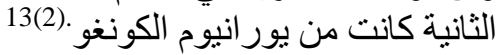

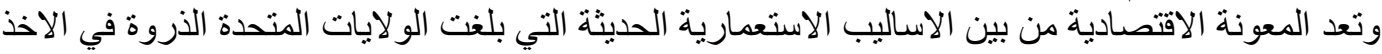

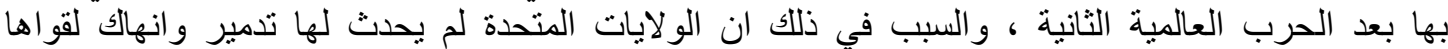

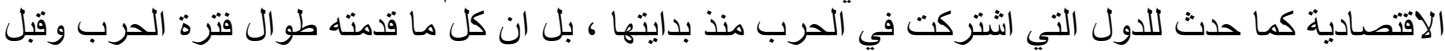

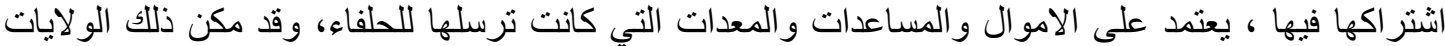

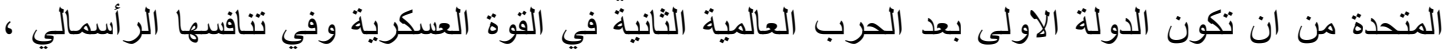

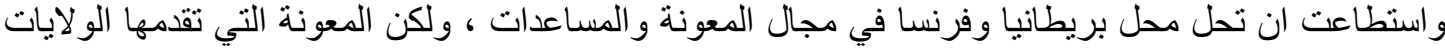

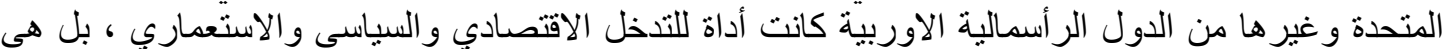

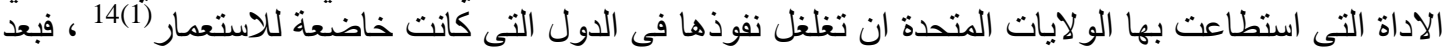

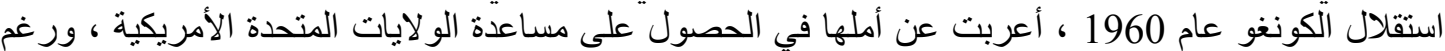

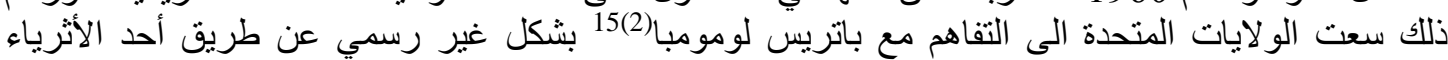

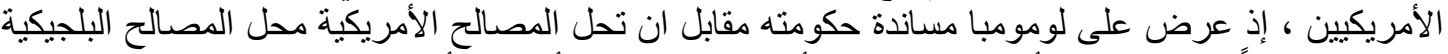

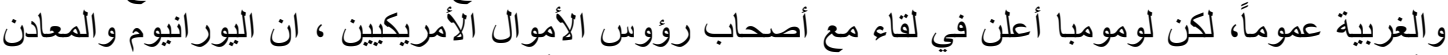

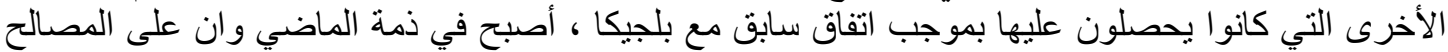

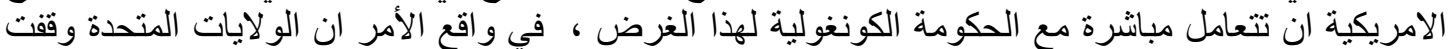

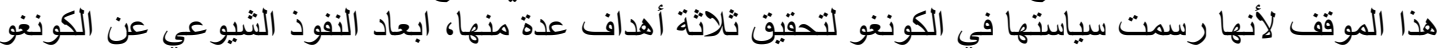

11(2) حسين عبد الحمبد احمد ، الاستعمار في القرن العشرين ، الهيئة المصرية العامة للكتاب ، الاسكندرية ، 1975 ، ص $.83-82$

${ }^{12}$ (1) George Wright, The destruction of a nation - united State's Polcy towards Angola Since

1945 , USA , 1997 , p. 19.

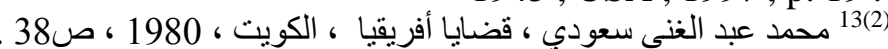

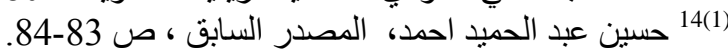
(15) باتريس لومومبا (1925-1961) : رئيس وزر اء أول حكومة كونغولية بعد الاستقلال ، ولاند في في إقليم كاساي من أسرة

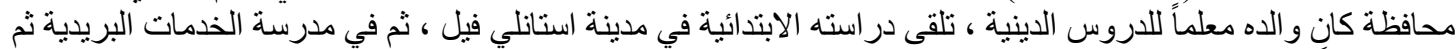

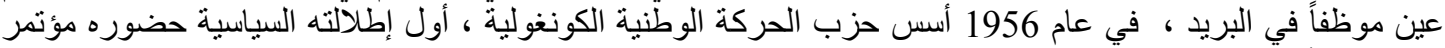

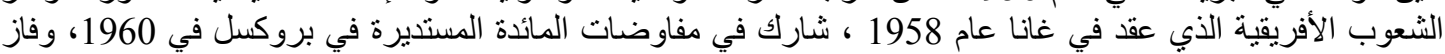

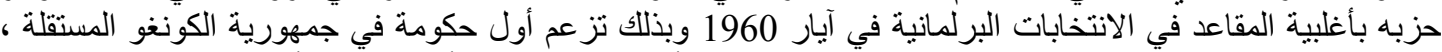

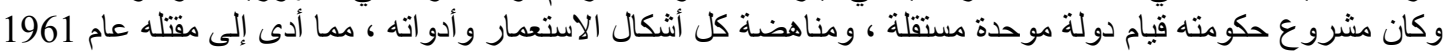

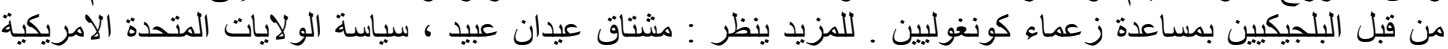

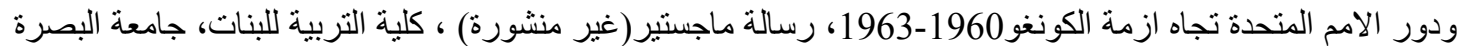

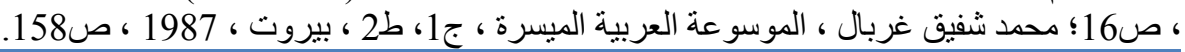




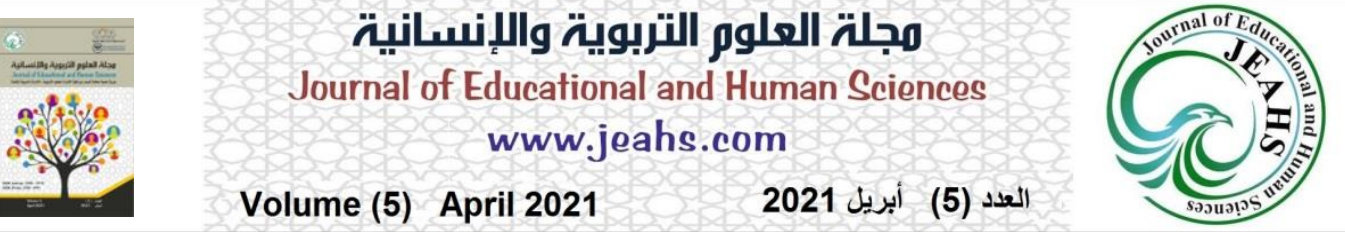

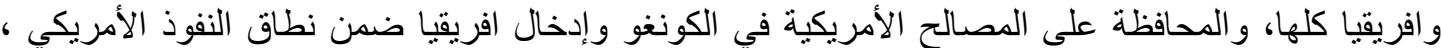
و الخروج من الحرب الدائرة بينها وبين المصالح البلجيكية والغربية عموما منتصرة، ليحل النفوذ الأمريكي النيكي

محلها.(1) منروجن

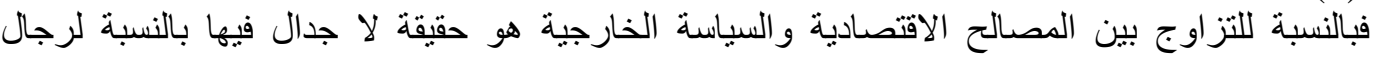

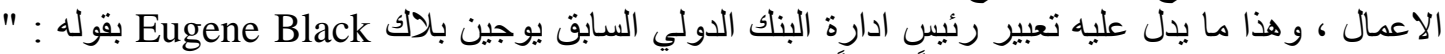

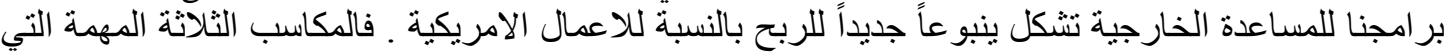

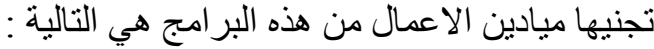

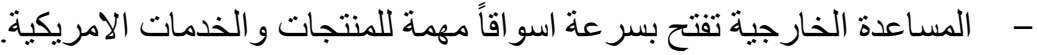
- - المساعدة الخارجية تمكن من تتمية اسواق جديدة عبر البحار للشركات الامريكية.

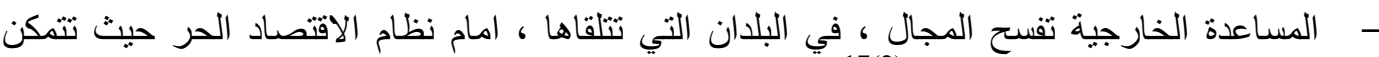

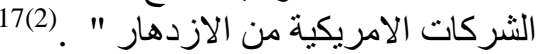

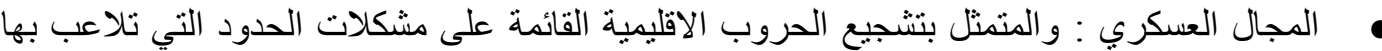

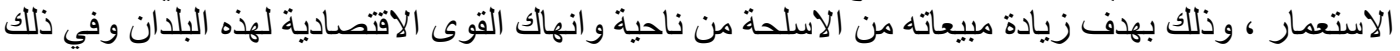

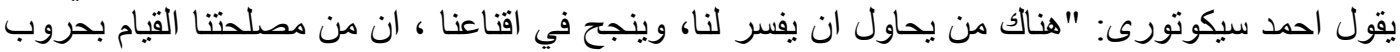
تصحيح للحدود واعادة الهيكل السياسي القديم لافريقيا ماقبل الاستعمار ، وهذا فئا ما فيلائم في الو اقع مصالح

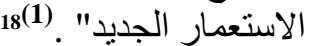

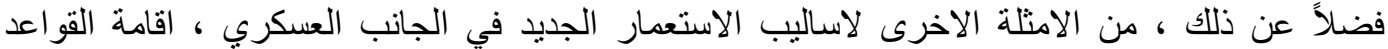

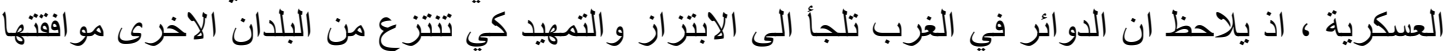

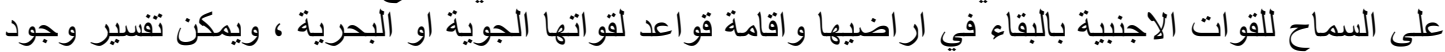

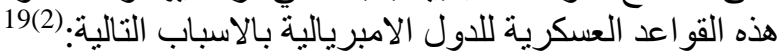

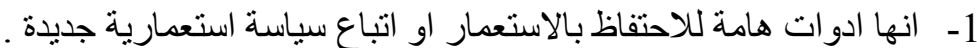

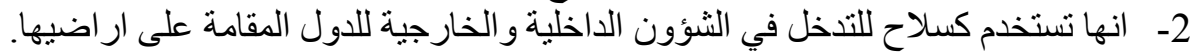

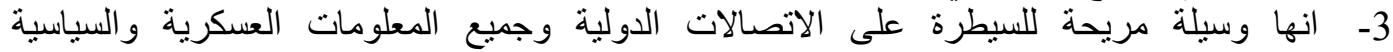
و الاقتصادية عن طريق التجسس. 4- انها تقدم على الار اضي الاجنبية مز ايا تجارية معينة للبلد الذي اقامها.

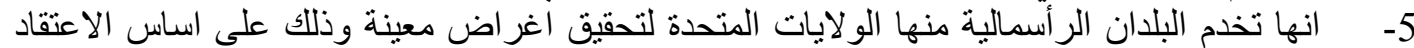

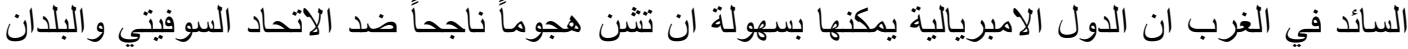

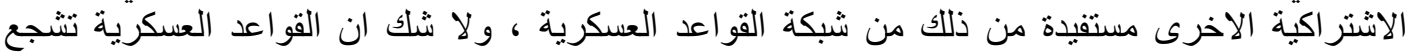

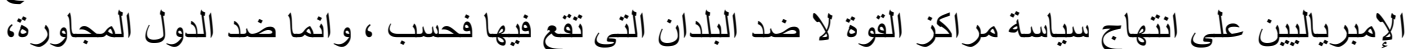

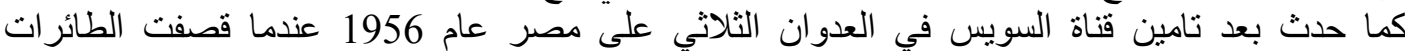

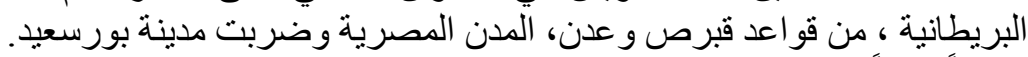

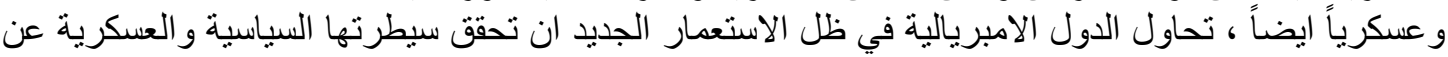

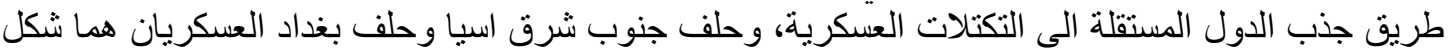

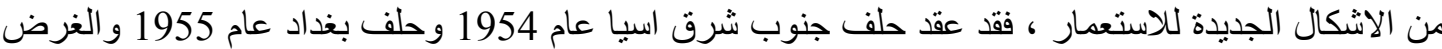
منهما الهجوم لا الدفاع فهما موجهان ضد الاتحاد السوفيتي وضد البندي البلاد التي كانت مستعمرة وتابعة في الماضي ،

16(1) حسين جبار شكر البياتي، النطورات السياسية في الكونغو 1960-1965، اطروحة دكتوراه(غير منشورة)، كلية

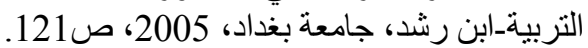

17 (2) E. R. Black, The Domestic Dividends of Foreign Aid , Columbia Journal of World Businss, No. 55,1965 , p.166.

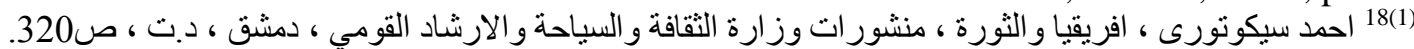

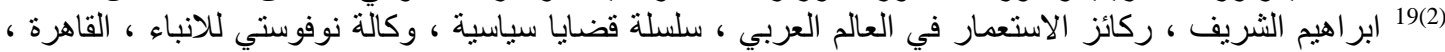


و غرض هذه الاحلاف العسكرية هو حماية وتقوية مناطق النفوذ القديمة التي كانت للقوى الاستعمارية في

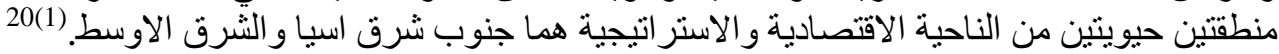

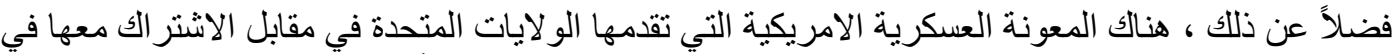

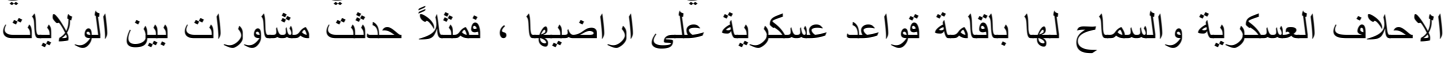

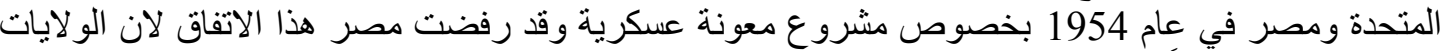

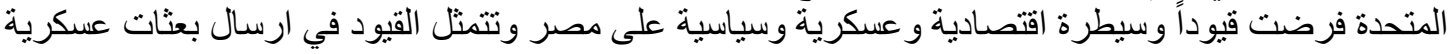

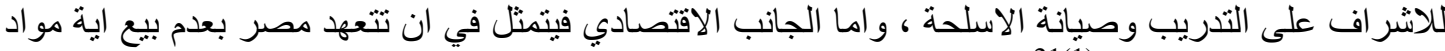
استر اتيجية للكتلة الثيو عية.

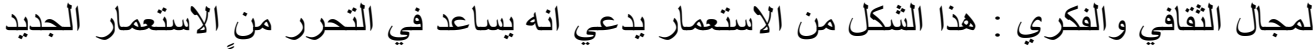

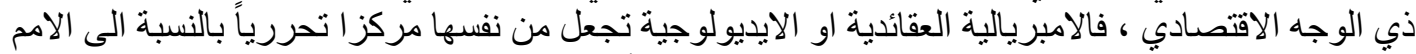

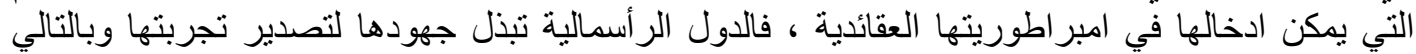

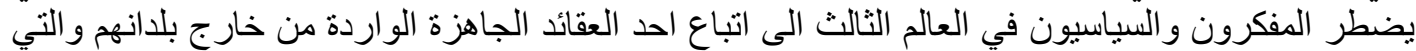

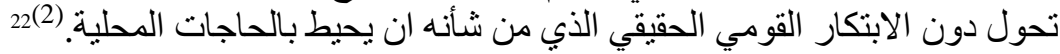

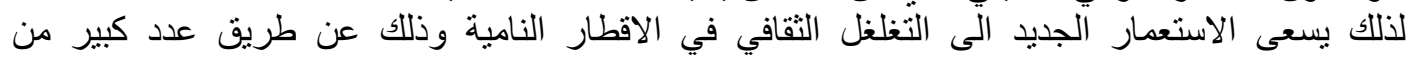

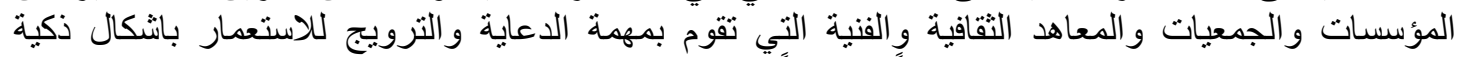

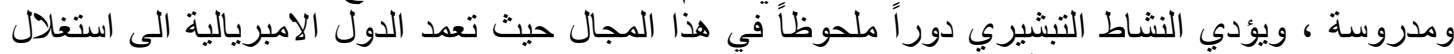

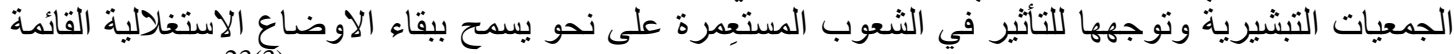

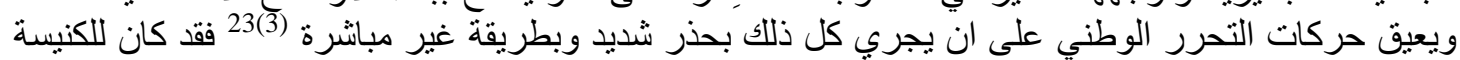

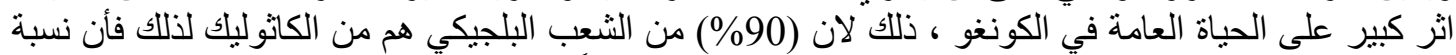

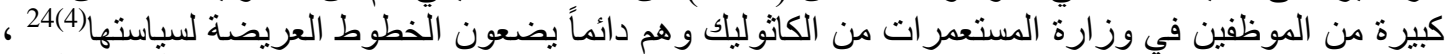

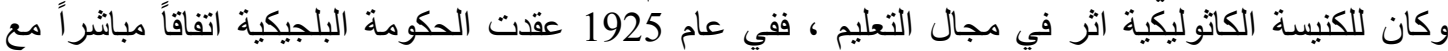

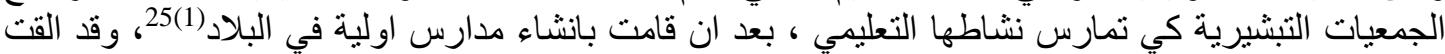

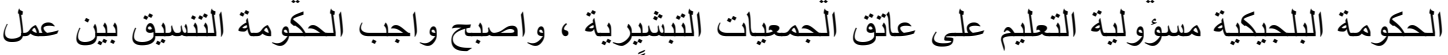

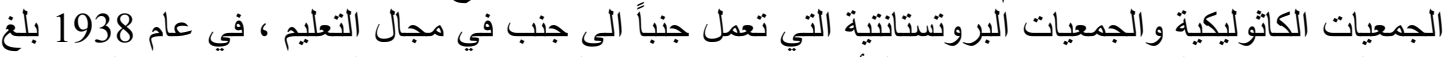

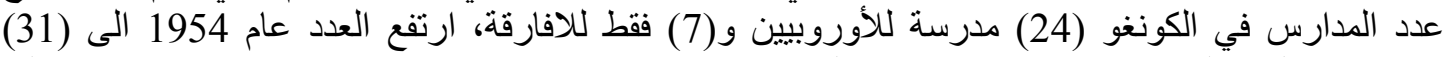

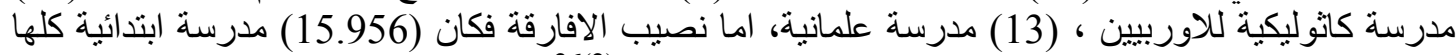

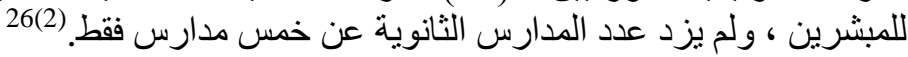

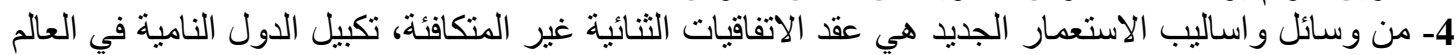

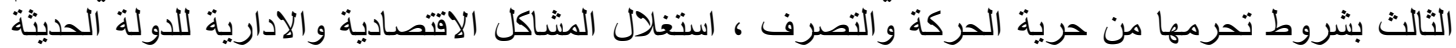

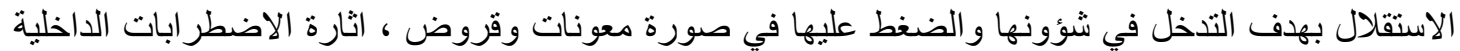

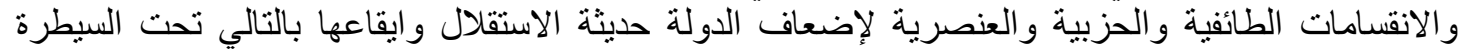

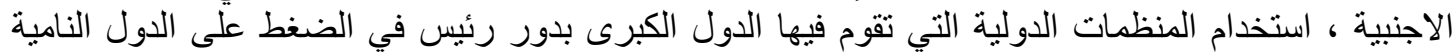

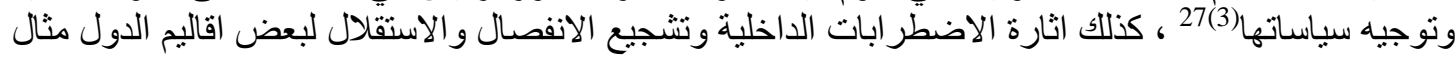

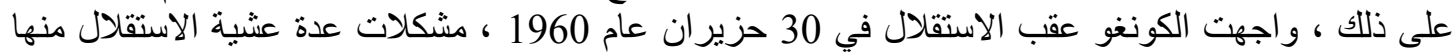

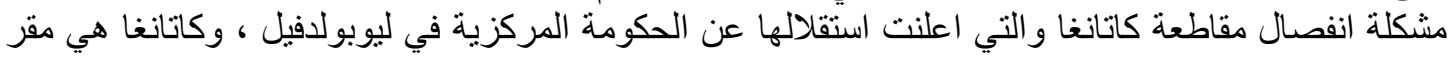

20(1)

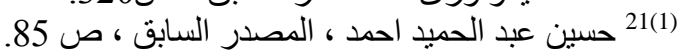

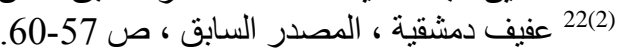

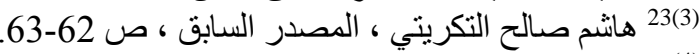

${ }^{24}$ Ruth Slade, Belgian Congo, London , 1960, p.203 ${ }^{(4)}$

25(1) محمود الثرقاوي ، الكونغو في ركب الحرية ، القاهرة ، 1960 ، ص19.

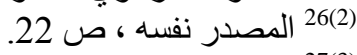

27(3) 2حمد عطبة الله ، المصدر السابق ، ص 59.52. 
الاستثمار ات البلجيكية الضخمة، ومصدر حو الي (60\%) من ثروة البلاد فهي غنية بالنحاس و اليور انيوم وقد كان النيان

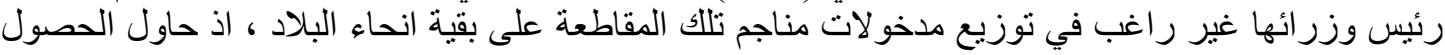

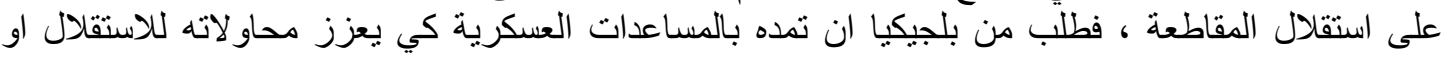

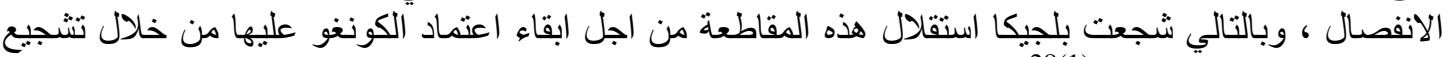

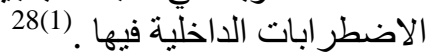

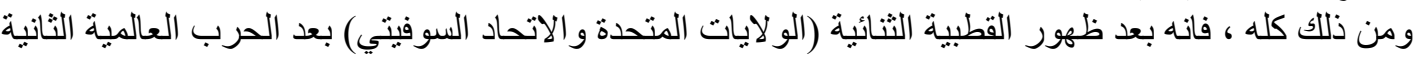

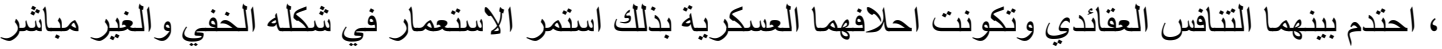

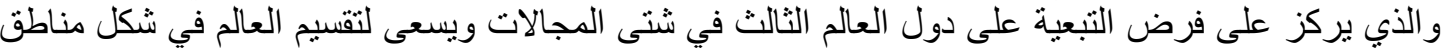

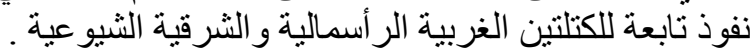

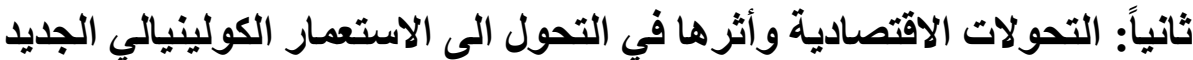

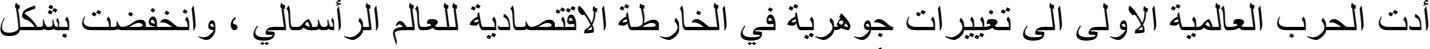

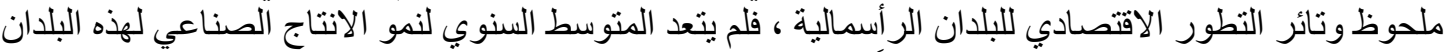

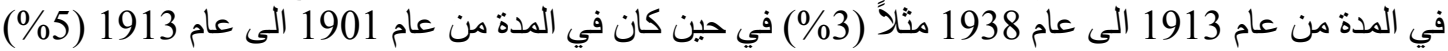

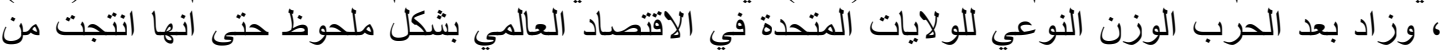

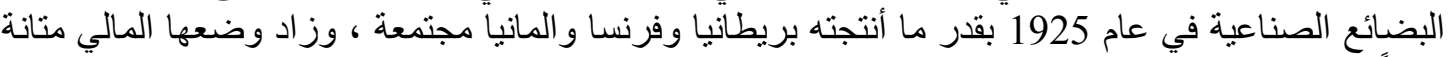

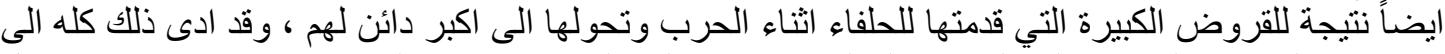

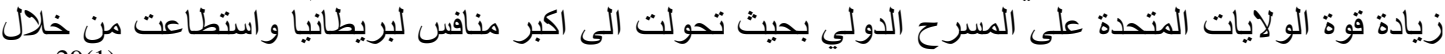

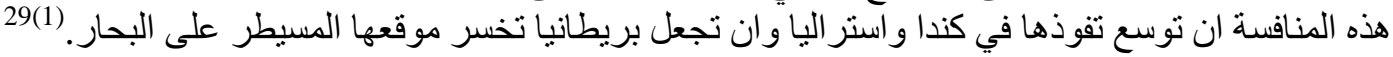

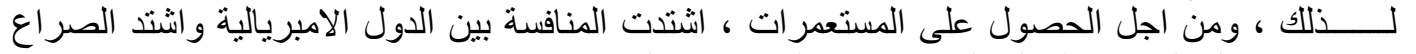

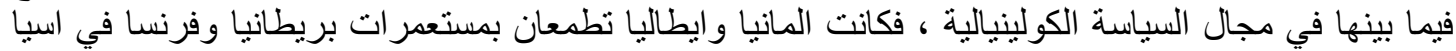

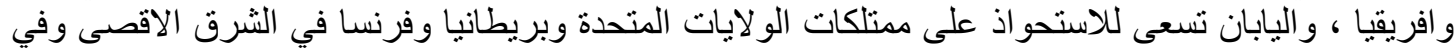

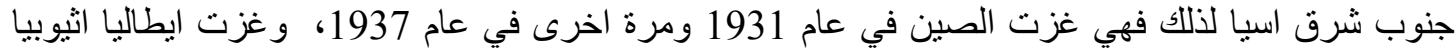

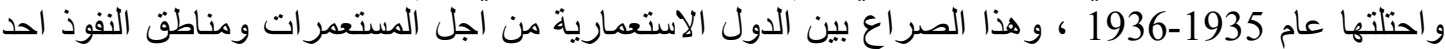
الاسباب التي ادت الى قيام الحرب العالمية الثانية .

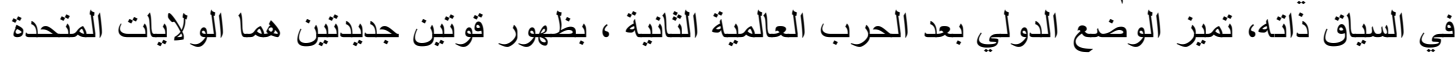

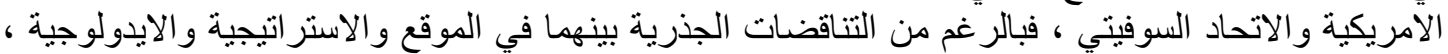

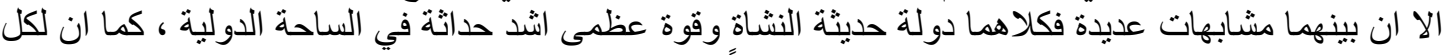

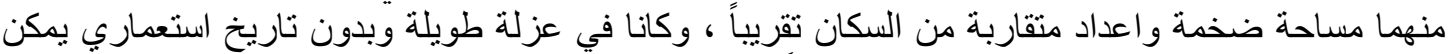

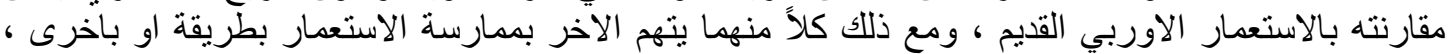

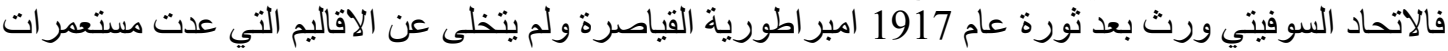

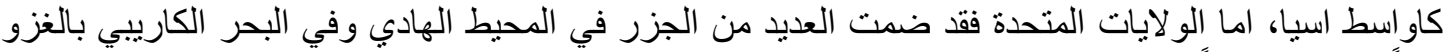

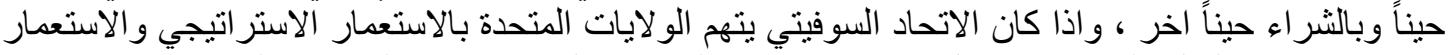

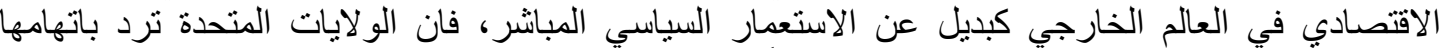
بالاستعمار المذهبي او الايديولوجي و الذي يعمل سر اً بالتخريب. (1) الإن

28(1) عبد الرزاق مطلك الفهد ، تاريخ حركات التحرر في العالم الثالث ، مديرية مطابع الجامعة ، الدوصل ، 1985 ،

1(11(13مال حمدان ، استر اتيجية الاستعمار و التحرير ، دار الثرق ، بيروت ، 1983، ص180-182. 


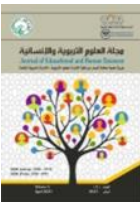

\section{مجلة العلوم التربوية والإنسانية}

Journal of Educational and Human Sciences www.jeahs.com

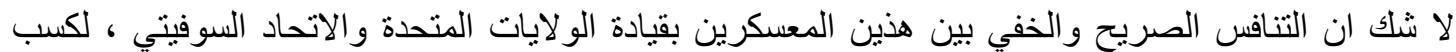

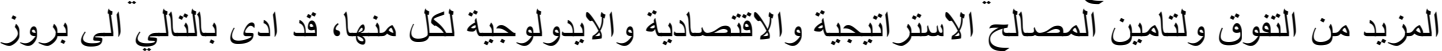

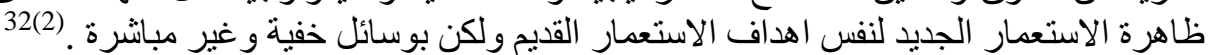

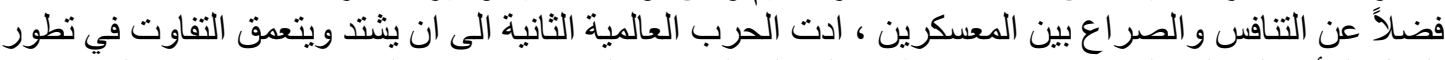

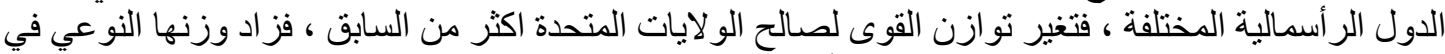

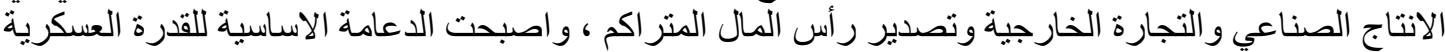

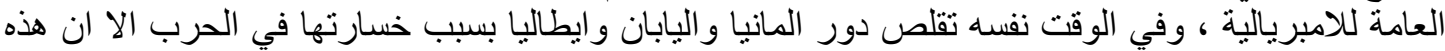

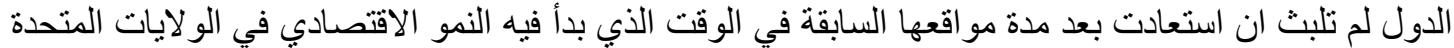

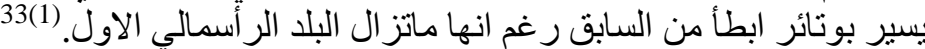

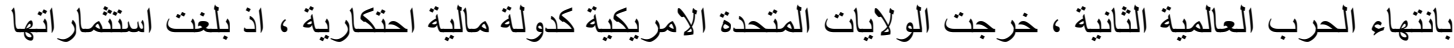

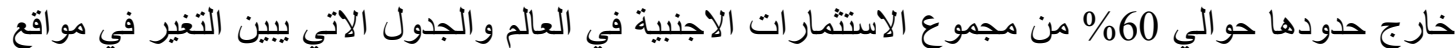

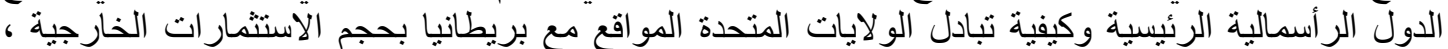

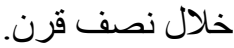

\begin{tabular}{|c|c|c|c|}
\hline 1960 & 1930 & 1914 & 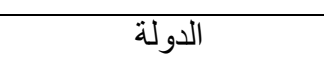 \\
\hline 59 & 35 & 6 & الو لايات المتحدة الامريكية \\
\hline 25 & 44 & 50 & بريطانيا \\
\hline 5 & 8 & 22 & فرنسا \\
\hline 1 & 3 & 17 & المانيا \\
\hline 4 & 6 & 3 & هو لندا \\
\hline 1 & 1 & 1 & 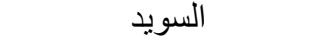 \\
\hline 5 & 3 & 1 & كندا \\
\hline $100 \%$ & $100 \%$ & $100 \%$ & المجموع \\
\hline
\end{tabular}

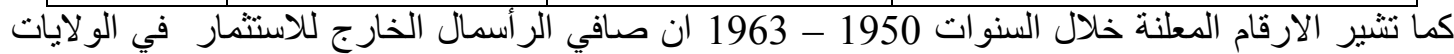

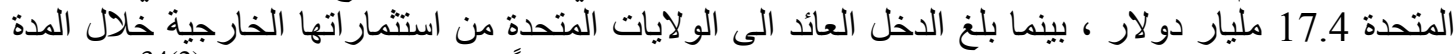

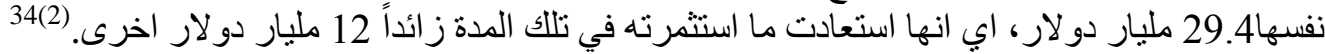

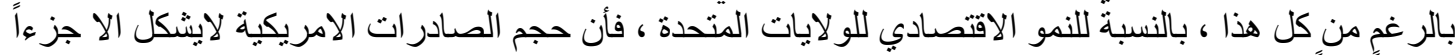

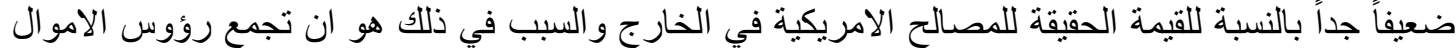

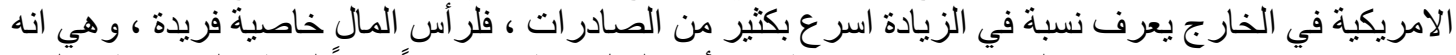

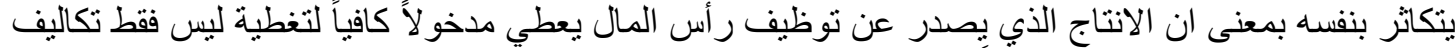

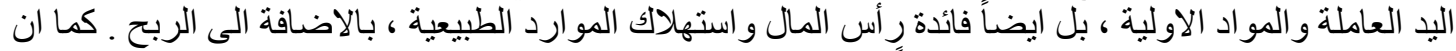

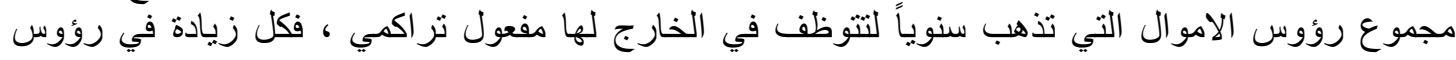




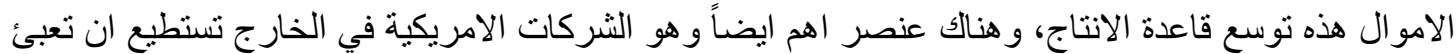

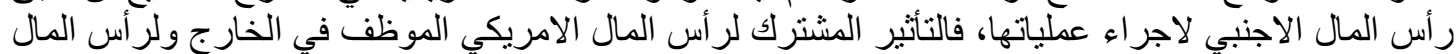

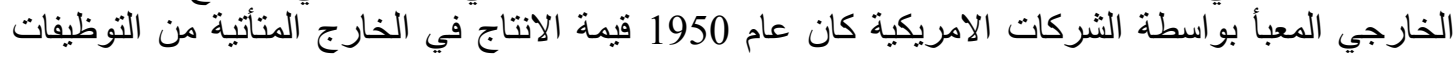

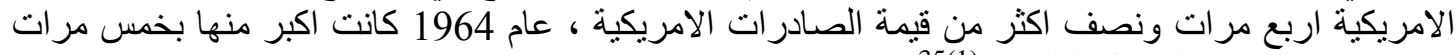

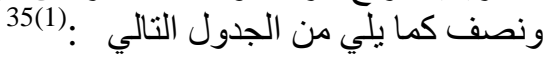

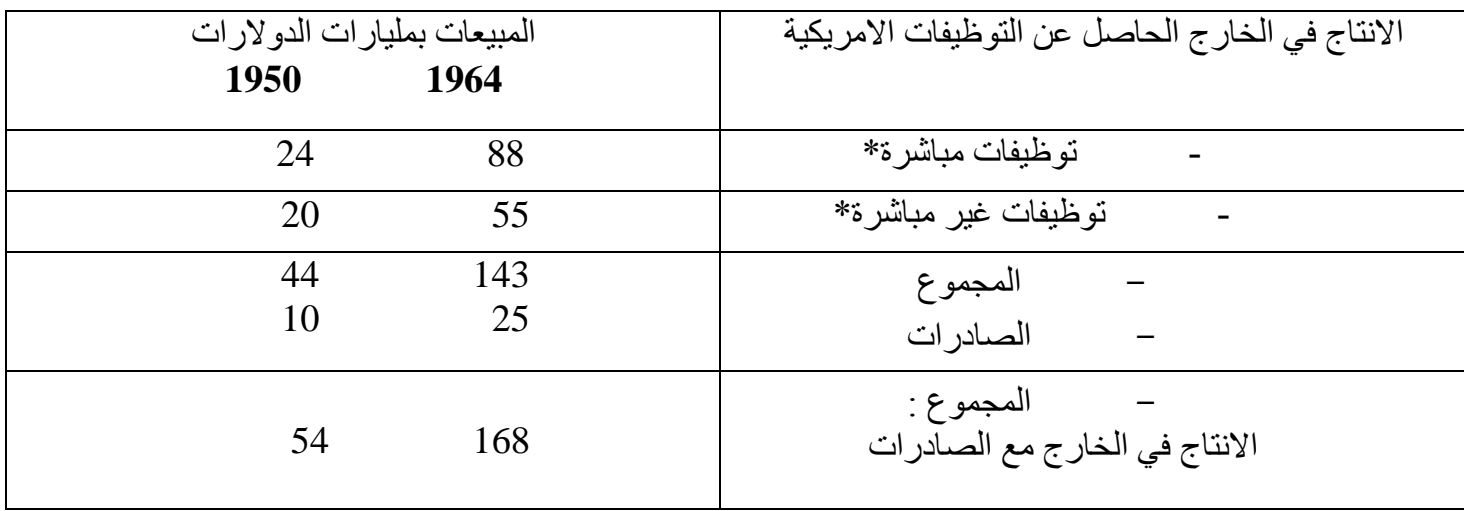

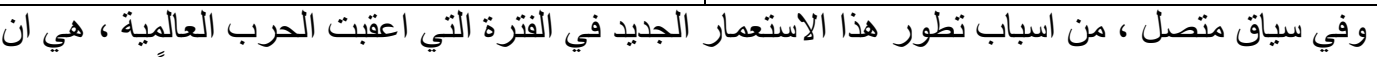

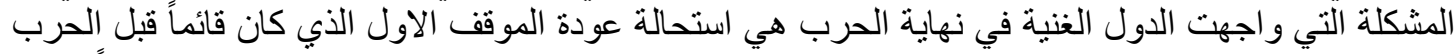

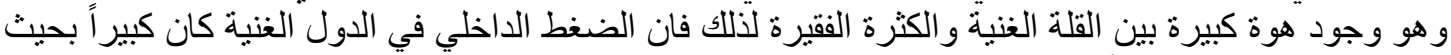

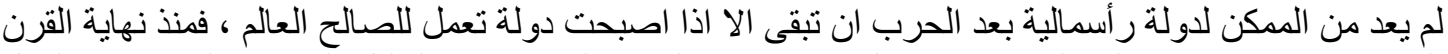

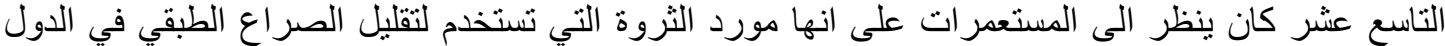

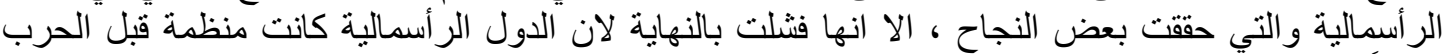

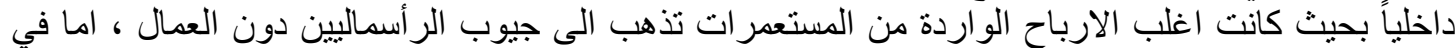

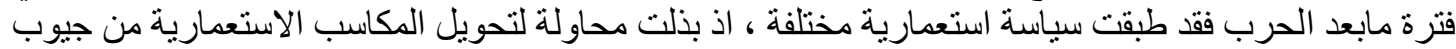

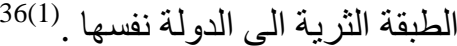

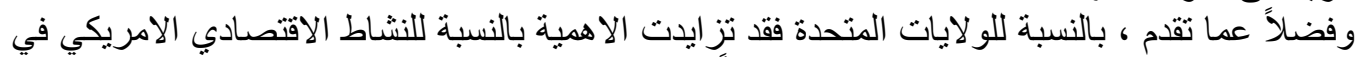

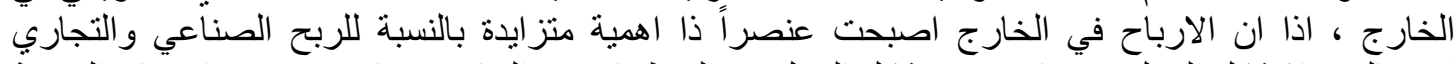

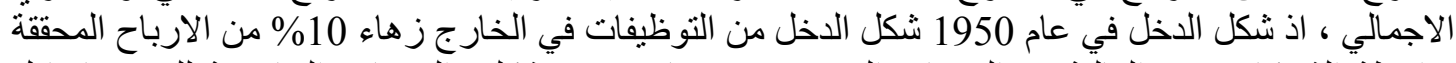

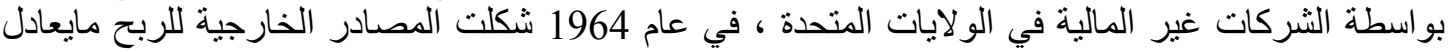

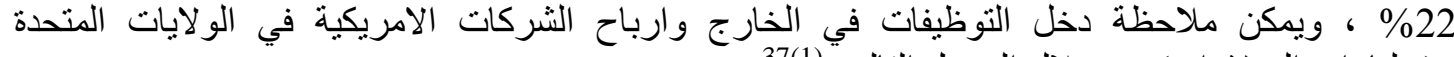

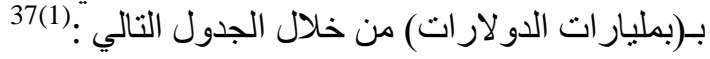

\begin{tabular}{|c|c|c|}
\hline دخل التوظيفات في الخارج| & ارباح الثركات غير المالية بعد دفع الضر ائب \\
\hline 21.7 & 2.1 & $\mathbf{1 9 5 0}$ \\
\hline 22.5 & 4.1 & $\mathbf{1 9 5 9}$ \\
\hline 36.1 & 7.8 & $\mathbf{1 9 6 5}$ \\
\hline
\end{tabular}

35(1) حمزة علوي و هاري ماكدوف ، الامبريالية الجديدة ، دار الطليعة للطباعة والنشر ، بيروت ، 1970 ، ص 74 - 75

*قصد بها المؤسسات او الثركات الفروع التي تملك الثركات الامريكية 25\% او اكثر من اسهمها. *التوظيفات الاخرى هي في اكثر ها مكونة من سندات او استهم لثركات اجنبية يملكها الفر اد اد او شركات امريكية.

$$
\text { (36(1) }
$$

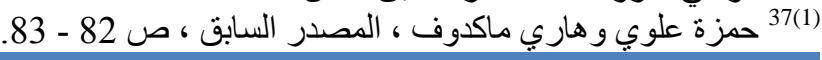




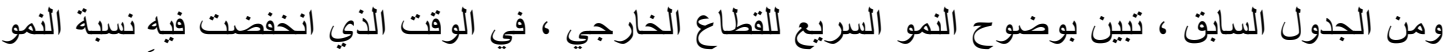

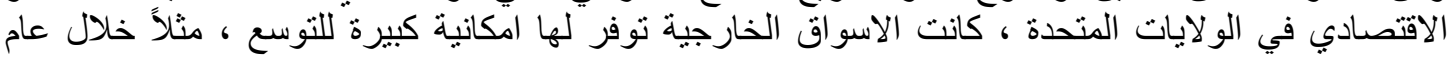

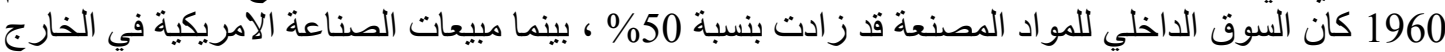

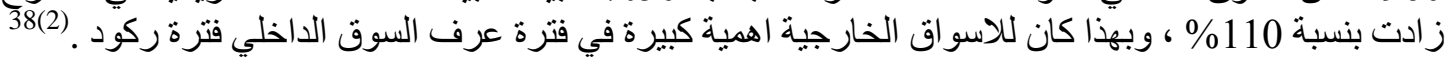

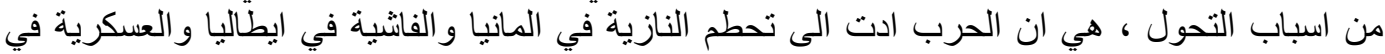

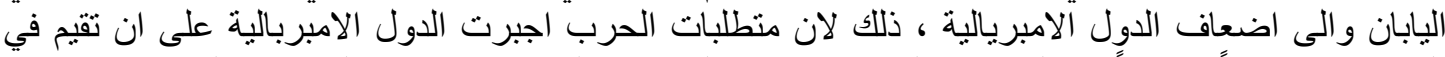

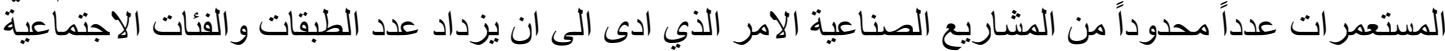

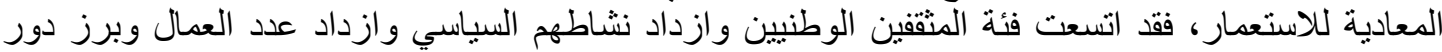

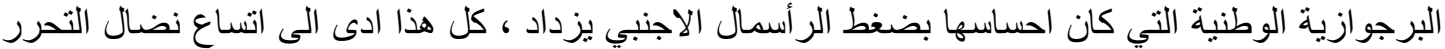

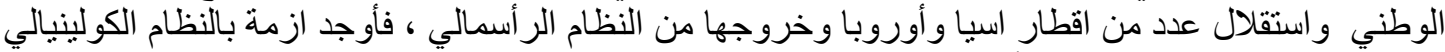

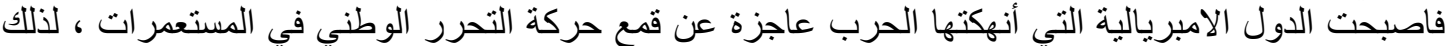

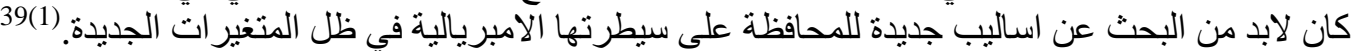

\section{ثُالثاً: الاستعمار الكولنيالي الجديد للكونغو}

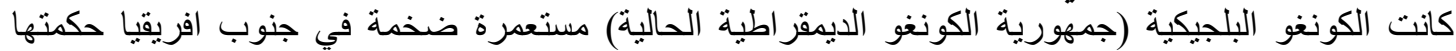

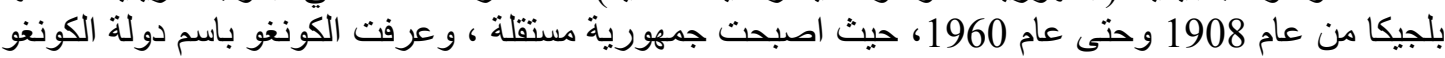
الحرة في الفترة بين عامي 1885 و 1908 ، و اديرت بصفتها ملكية خاصة بالملك ليوبولد الثاني ملك بلجيكيا 40(2)

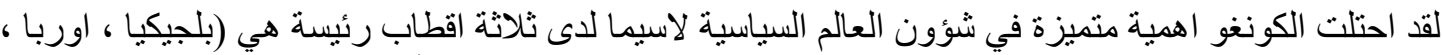

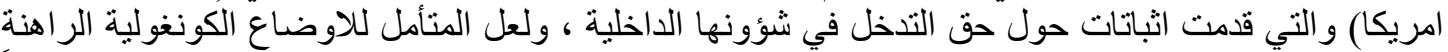

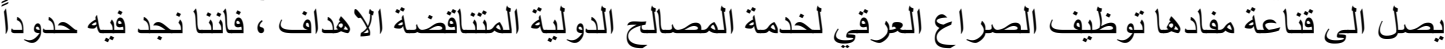
اقليمية ، وصر اعات قومية ودينية ، وطبقات اجتماعية وموارد طبيعية، لذلك فهي محل انظار الدول الاستعمارية الإلية

لابد من الاشارة بأن لكل توسع استعماري العديد من الدو افع الاقتصادية الاستر اتيجية التي تحدد معالمه الاساسية الاستية

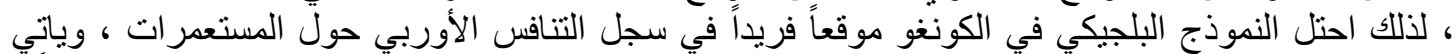

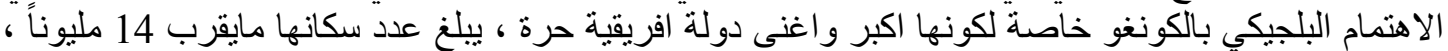

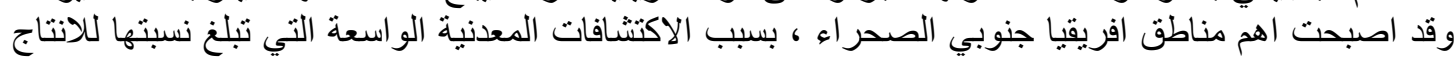

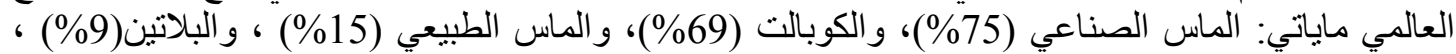

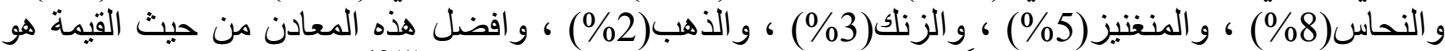

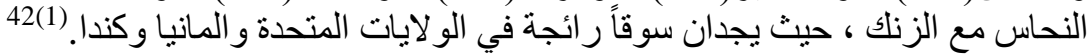

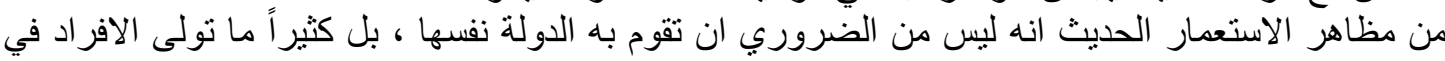

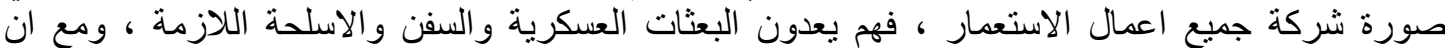

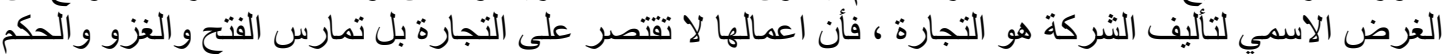

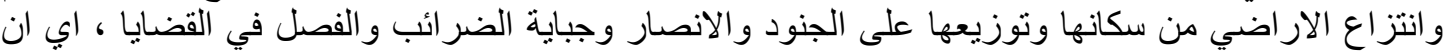

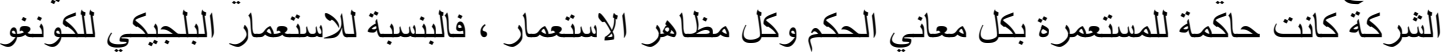

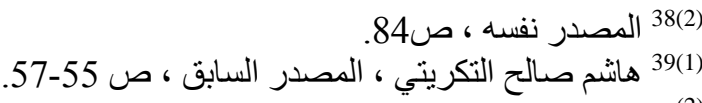

${ }^{40}$ G.W.Prothero, Belogian Congo, H.M.Stationery office , London, 1920, p.4. ${ }^{(2)}$ 191(3) جان بول سارنر ، الاستعمار الجديد ، نرجمة : عايدة وسهيل ادريس ، ط2 ، منشورات دار الاداب ، بيروت ،

42(1) شوفي عطا الله الجمل ، تاريخ افريقيا الحديث و المعاصر ، ط2 ، دار الز هر اء للنشر و التوزيع، 2002 ، ص135. 


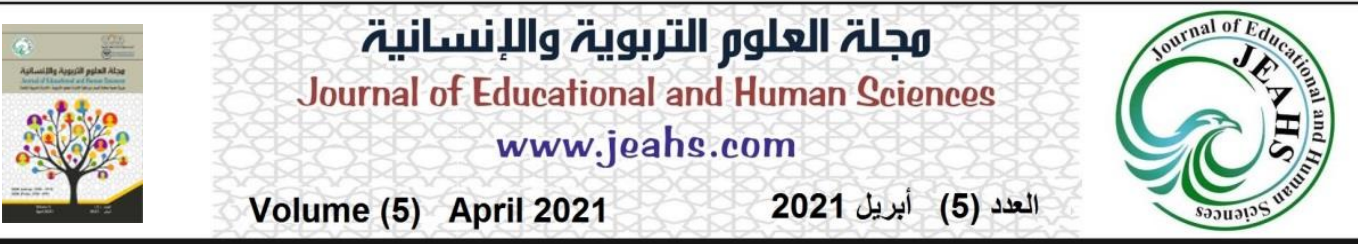

، فأن الملك البلجيكي ليوبولد الثانية لم يرد ان تتولى بلجيكا استعمار الكونغو ، بل انشأ لذلك هيئة مستقلة

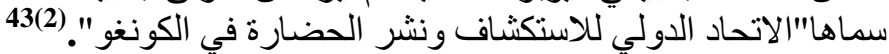

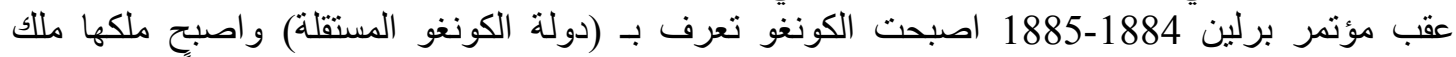

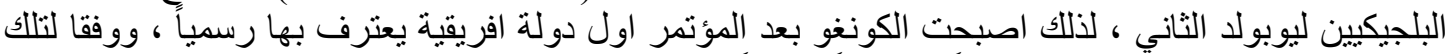

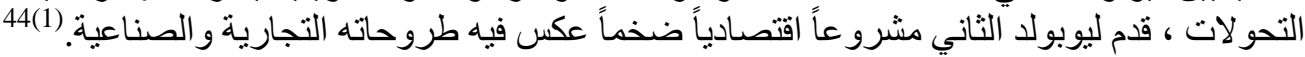

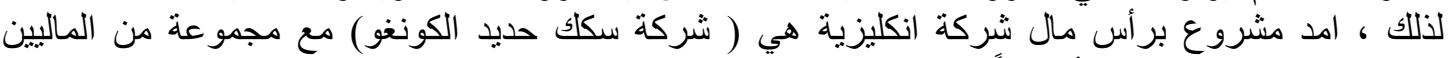

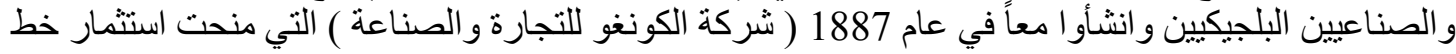

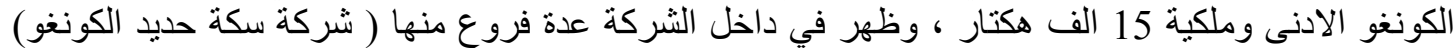

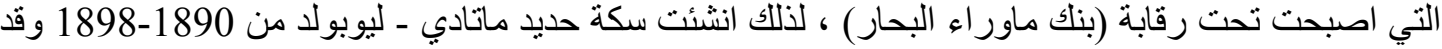

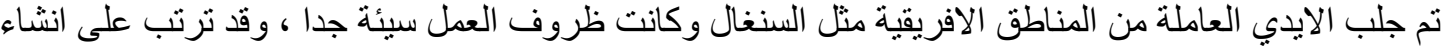

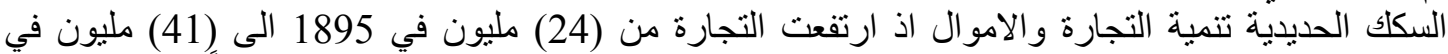

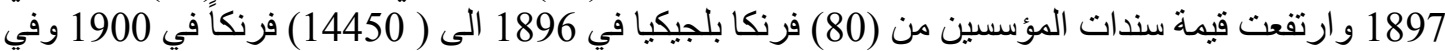

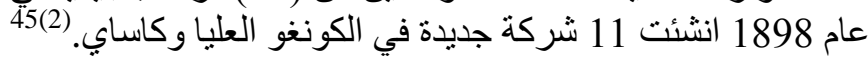

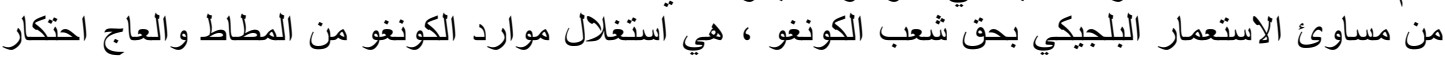

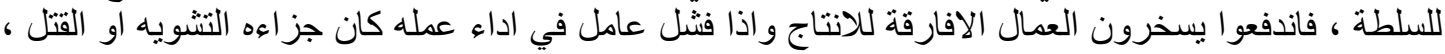

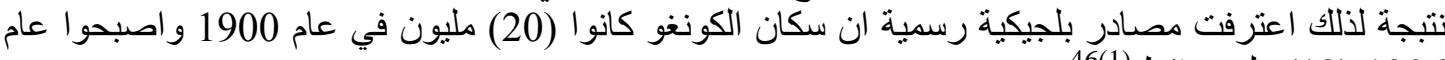

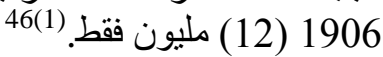

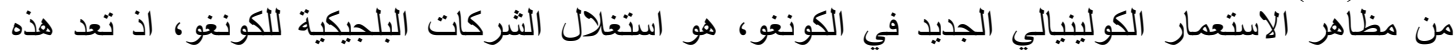

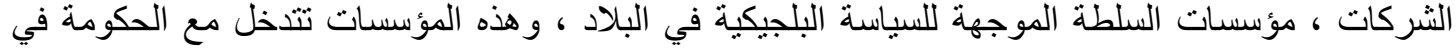

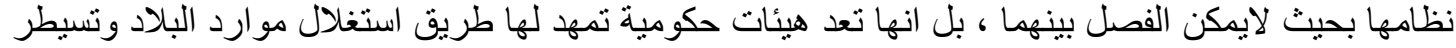

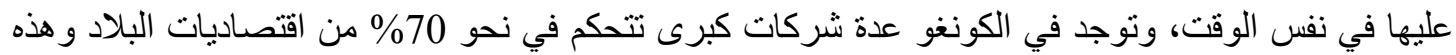

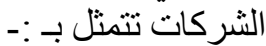

1- شركة بروكسل للتمويل و الصناعة (برومتينا) ، و هي تتحكم في بنك بروكسل و عدة مؤسسات صناعية.

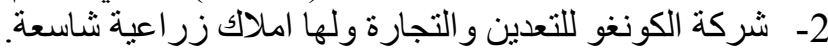

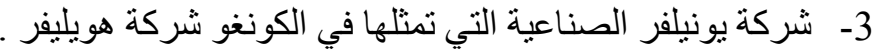

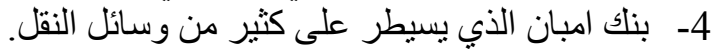

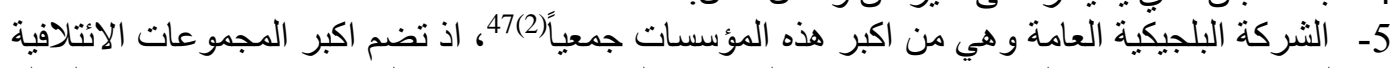

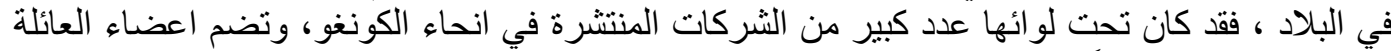

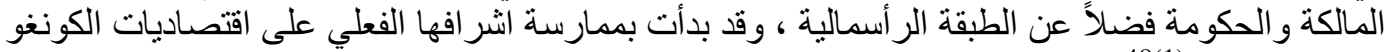

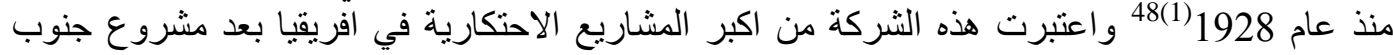

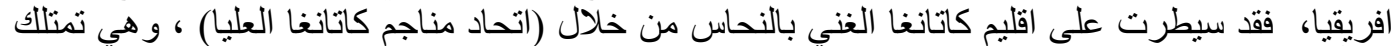

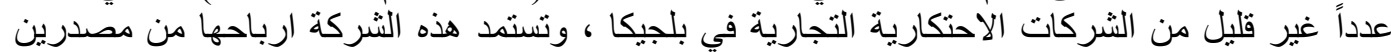

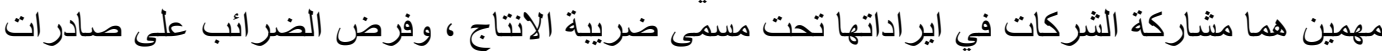

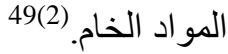

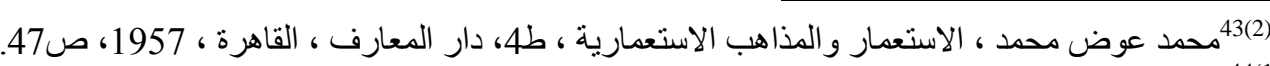

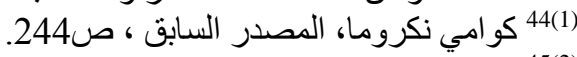

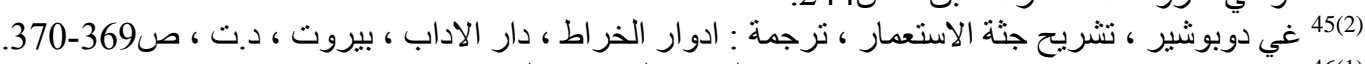

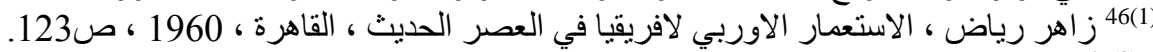

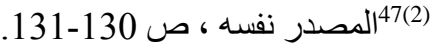

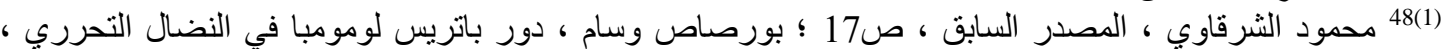

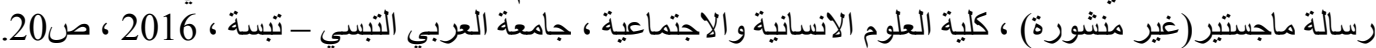

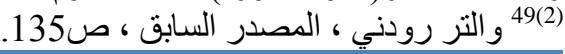




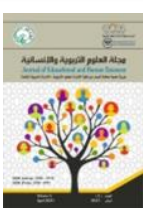

مجلة العلوم التربوية والإنسانية

Journal of Educational and Human Sciences www.jeahs.com

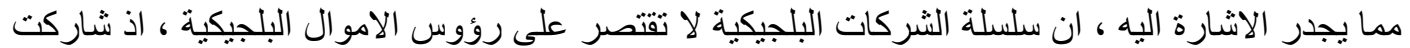

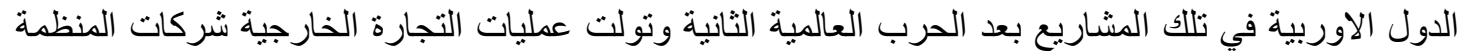

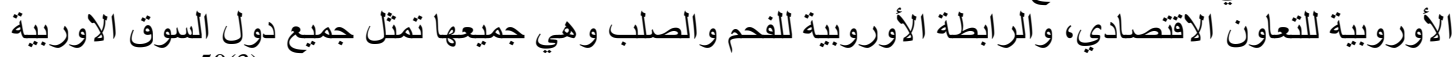

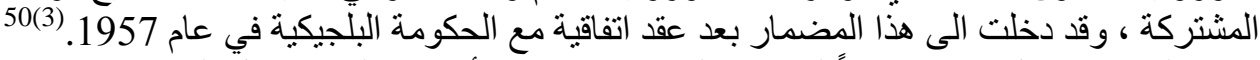

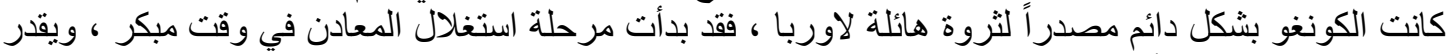

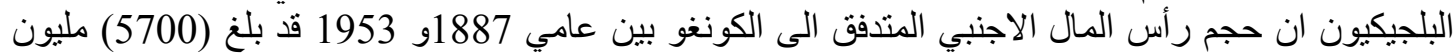

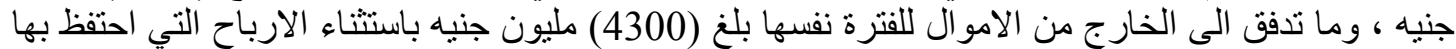

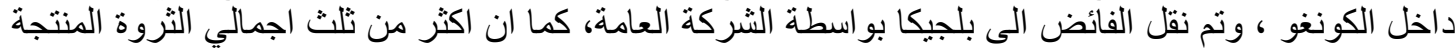

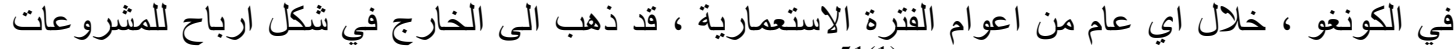
الكبرى ومرتبات للعاملين بها من الاجانب.

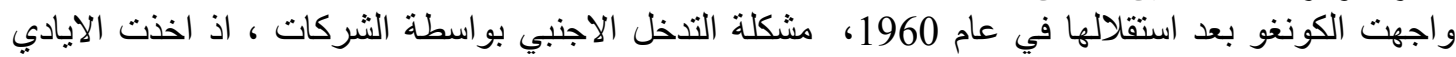

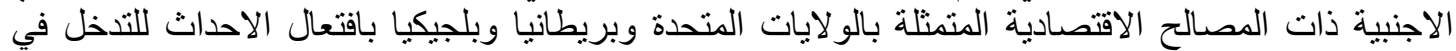

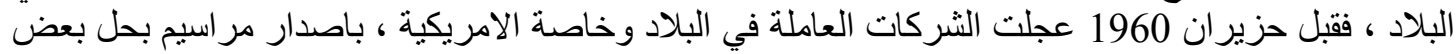

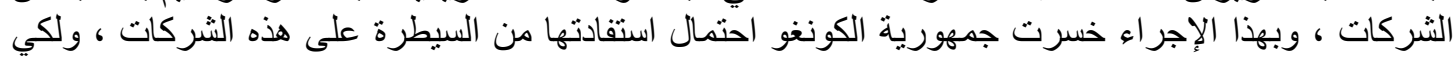

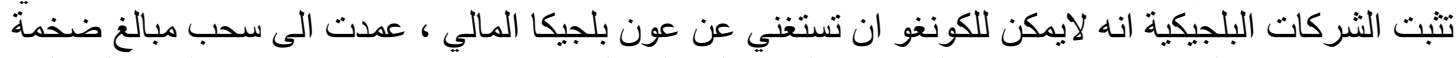

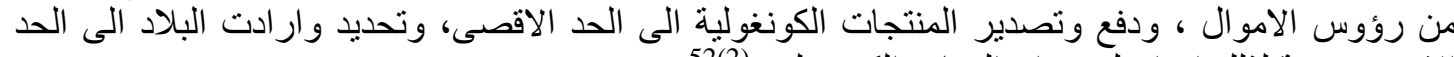

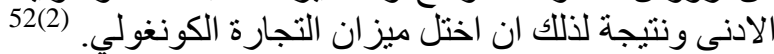

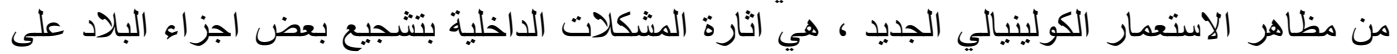

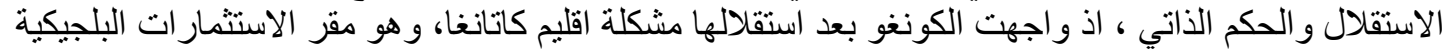

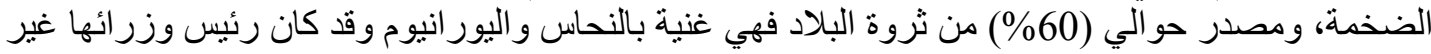

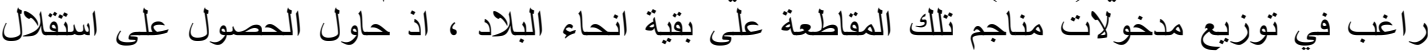

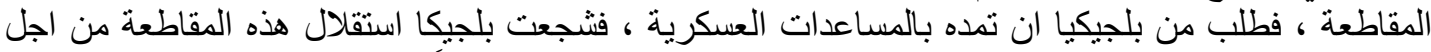

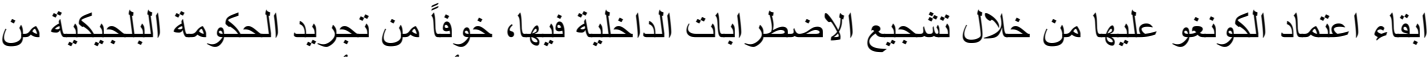

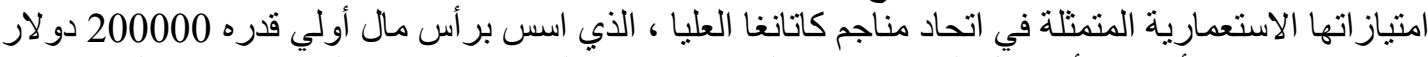

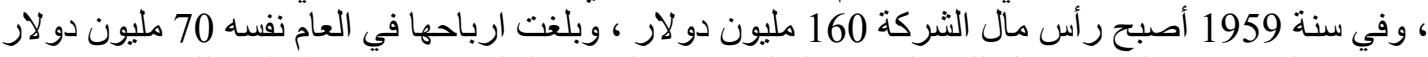

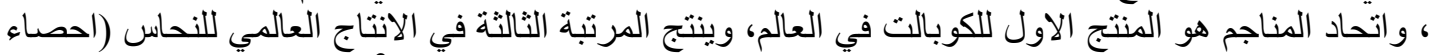

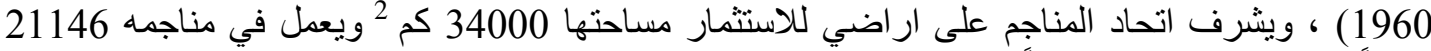

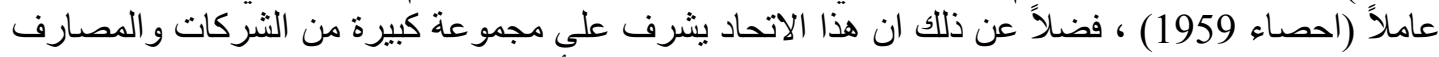

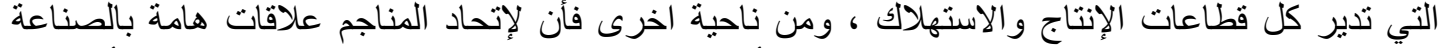

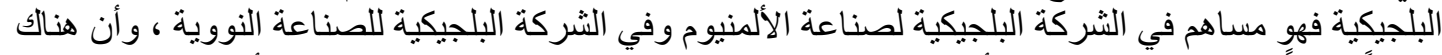

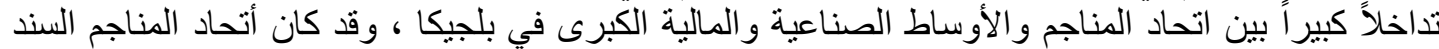

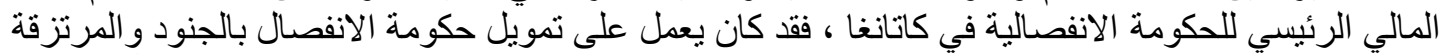

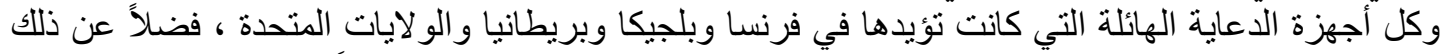

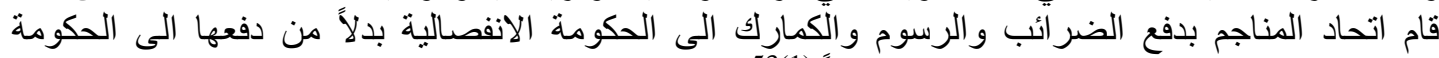
المركزية و التي تصل التى 7 ملايين دو لار سنوياً.

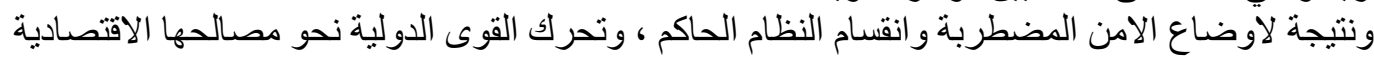
المهددة بالخطر ، وقد ساهدت القيادة السياسية ذات الميول المختلفة في صياغة احداثيات الصراع الصراع الدولي ،

(50(3) إن الم $52(2)$

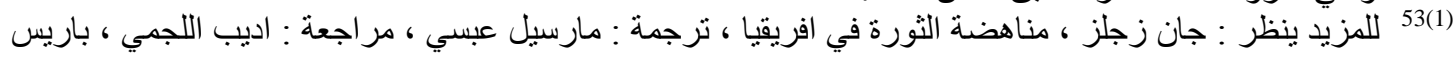




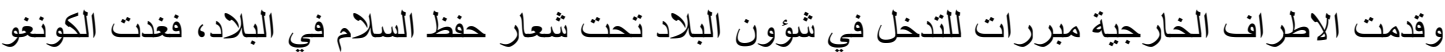

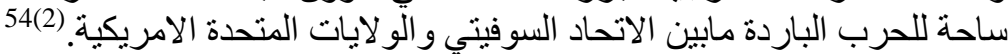

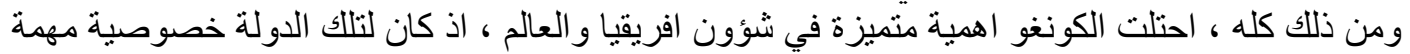

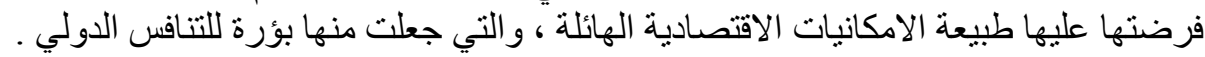

الخاتمـة:

ان نهاية الاستعمار التقليدي لم تكن في و اقع الامر نهاية لظاهرة الاستعمار ، لانه وبعد ظهور القطبية الثنائية

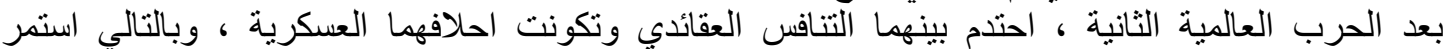

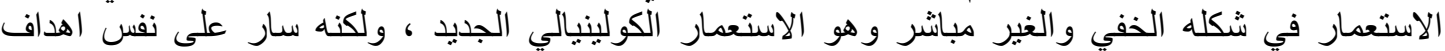

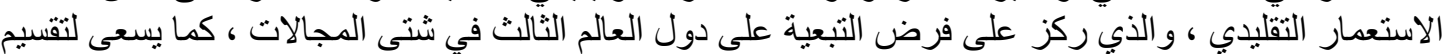

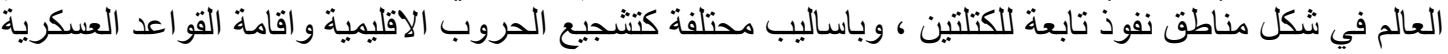

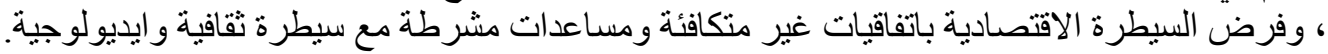

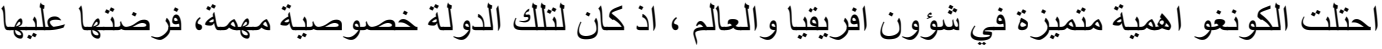

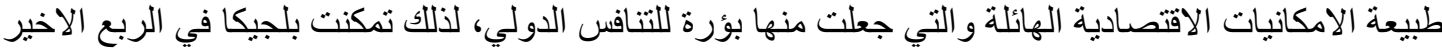

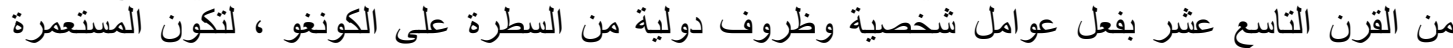

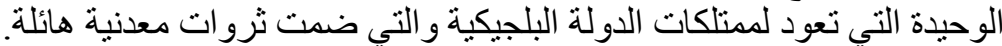

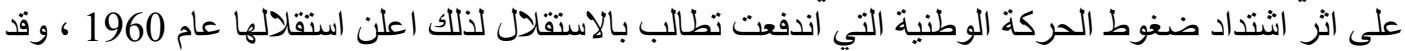

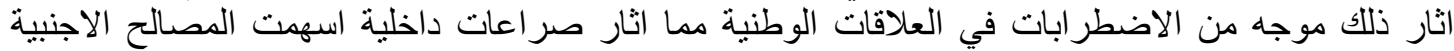

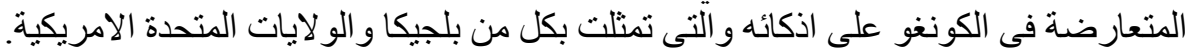

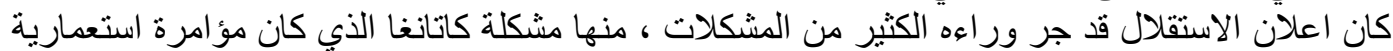

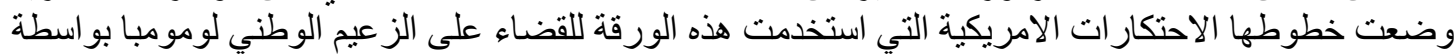

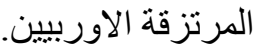

\section{المصادر}

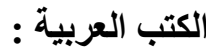

1- ابر اهيم الثريف ، ركائز الاستعمار في العالم العربي ، سلسلة قضايا سياسية ، وكالة نوفوستي للانباء ،

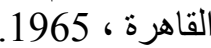

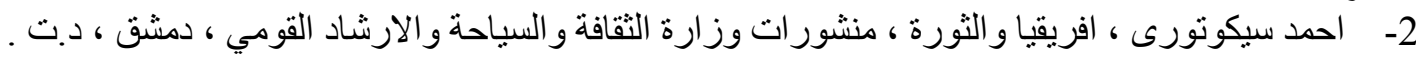

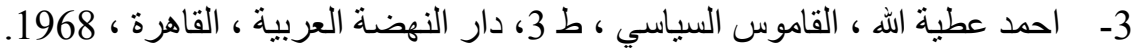

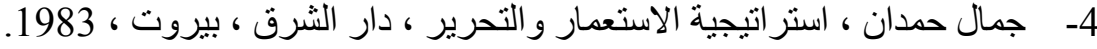

5- حسين عبد الحميد احمد ، الاستعمار في القرن العشرين ، الهيئة المصرية العامة للكتاب ، الاسكندرية ،

6- حمزة علوي و هاري ماكدوف ، الامبريالية الجديدة ، دار الطليعة للطباعة و النشر ، بيروت ، 1970 ، 1970.

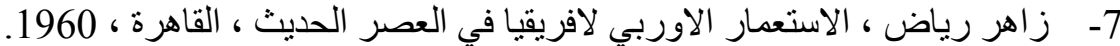

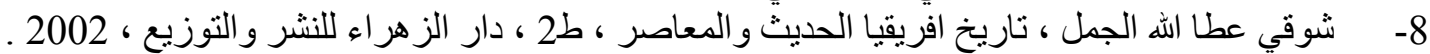

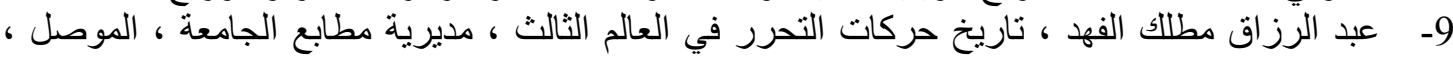

10- عفيف دسقية ، تجربة العالم الثالث ، ط 2، سلسلة الدر اسات الاستر اتيجية ، معهد الانباء العربي ، بيروت ،

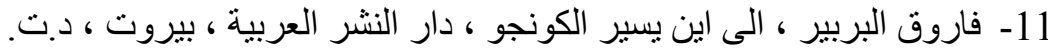

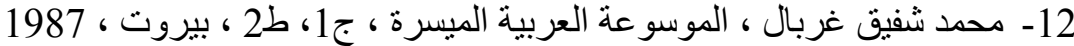
13- محمد عبد الغني سعودي ، قضنايا أفريقيا ، الكويت ، 1980.

54(2) فاروق البربير ، الى اين يسير الكونجو ، دار النشر العربية ، بيروت ، د.ت ، ص 14. 


\section{مجلة العلوم التربوية والإنسانية}

Journal of Educational and Human Sciences www.jeahs.com

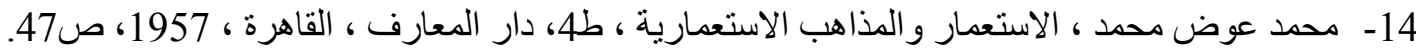

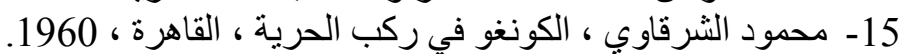

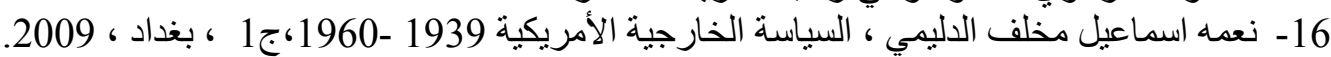

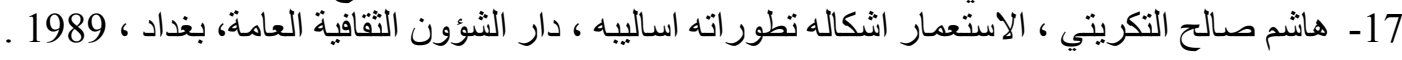

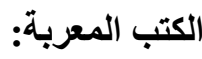

1- جالك ووديس ، جذور الثورة الافريقية ، ترجمة : احمد فؤاد بلبع ، القاهرة ، 1971.

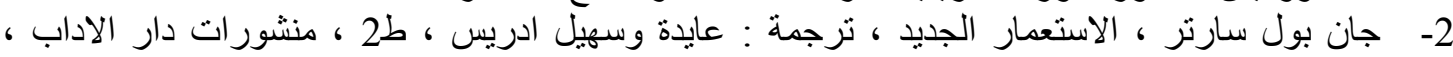

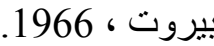

3- جان زجلز ، مناهضة الثورة في افريقيا ، ترجمة : مارسيل عبسي ، مراجعة : اديب اللجمي ، باريس ، 1963

4- رينشارد بارنث ، حروب التدخل الامريكية في العالم ، ترجمة : منعم النعمان ،ط1 ، دار ابن خلدون ل للطباعة و النشر ، بيروت ، بارن ، 1974.

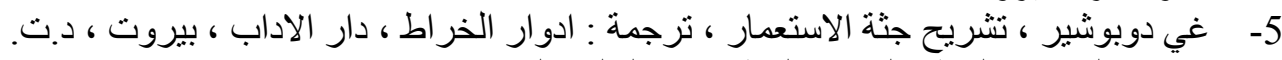

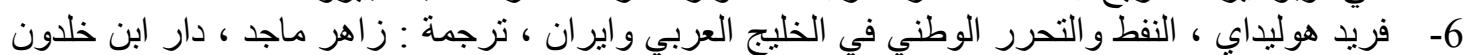

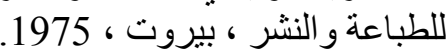

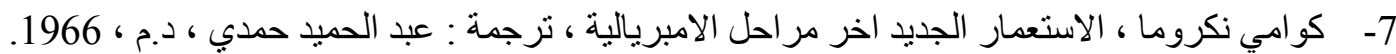
8- و التر رودني ، اوربا والتخلف في افريقيا ، ترجمة : احمد القصبر ، المجلس الوطني للتقافة ، الكويت ،

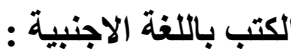

1. E. R. Black, The Domestic Dividends of Foreign Aid, Columbia Journal of World Businss, No. $55,1965$.

2. Ruth Slade, Belgain Congo, London, 1960.

3. G.W.Prothero, Belogian Congo, H.M.Stationery office, London, 1920 .

4. George Wright, The destruction of a nation - united State's Polcy towards Angola Since 1945 , USA, 1997.

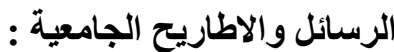
1- بورصاص وسائ ، الاطليح الجامعة باتريس لومومبا في النضال التحرري ، رسالة ماجستير(غير منشورة) ، كلية العلوم

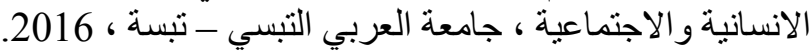

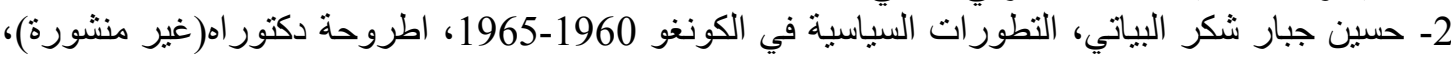

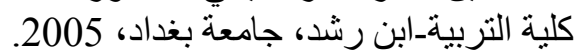

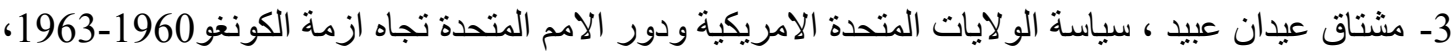

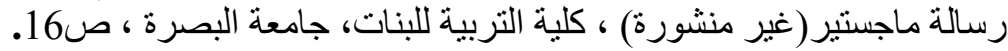

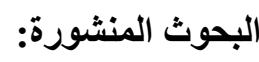

1- محمد محمد حقي ، الكونغو من لومومبا الى الى موبوتو ، مجلة السياسة الدولية ، العدد(9) ، 1967. 